\title{
Moving Films: Visualising Film Flow in Three European Cities in 1952
}

\begin{abstract}
This article is an international collaboration focusing on three European port cities - Antwerp (Belgium), Gothenburg (Sweden) and Rotterdam (Netherlands) - in 1952, during the golden age of cinema prior to the rise of television. The objective is to test an approach for making transnational comparisons of distribution and exhibition based on film programming data. We use a mixed-method approach that combines data visualisations based on a simple network analysis and time plot visualisations. Our aim is to show how these visualisations can be helpful in characterising and comparing cinema markets in an attempt to answer the question of how films move through a city from one cinema to the other and how this flow can be characterised and compared.
\end{abstract}

\section{Keywords}

film programming; new cinema history; comparative history; data visualisation; film distribution

\section{Introduction}

In 2016, film scholar Deb Verhoeven highlighted the problem that datasets used for digital cinema research are usually collected on a national or subnational level. She writes: 'While the proliferation of these digital case studies has produced a great deal of methodological innovation in cinema studies, this disjointed approach has also resulted in a significant deficit in our understanding of the international nature of the cinema. ${ }^{1}$ National approaches to research are traditionally the default geopolitical unit of study in the humanities. This is particularly problematic for studies of the film industry as, from its inception, its networks have been international in scope. Furthermore, Verhoeven is pessimistic about the prospect of interoperating extant data collections developed independently of one another.

Notwithstanding Verhoeven's legitimate concerns, in recent years a small but steady output of historical studies of (trans)national comparisons of cinema cultures and patterns of film distribution 
and exhibition has emerged. ${ }^{2}$ Indeed, research activity in this area seems to be growing. To mention a few examples: the format of the datasets and methods developed for the pioneering Belgian project The 'Enlightened' City has been replicated in studies of film cultures in Central and South America, offering opportunities for comparisons ${ }^{3}$ in the UK, a comparative project about European cinema audiences is running for which harmonised datasets have been created $;{ }^{4}$ in Frankfurt and Amsterdam, workshops are being organised on how to harmonise datasets and make them comparable. ${ }^{5}$ In other words, a number of transnational collaborations are either in progress or in the process of becoming established.

This article is a collaborative project, based on the film programming datasets collected for a variety of different national or city-based projects. We elaborate on this further in the section in which the dataset is described. The objective is to use simple Gephi network visualisations for transnational comparisons of distribution and exhibition practices. ${ }^{6}$ The Gephi visualisation will show the networks existing between cinemas by means of films that moved from one cinema to another. To better understand the patterns of these movements, we developed a second visualisation which illustrates the time lapses between the showing of a movie in one cinema and the next. Taken together, we demonstrate how these visualisations can be helpful in describing and comparing cinema markets. Our aim is to show the methods by which films moved through three European cities - Antwerp (Belgium), Gothenburg (Sweden) and Rotterdam (Netherlands) - from one cinema to another during the course of a single year (1952).

The three cities of our sample - Antwerp, Gothenburg and Rotterdam - are all among the larger cities in their respective countries. They are industrialised second tier cities which all happen to be large sea ports, with features that place them in between capital cities with their special economic, social and cultural status, and smaller urban locations. In Europe, medium-sized, historically stable urban centres - less sprawled in the 1950s than they are today - encompass most of the European population. ${ }^{7}$ However, the choice of cities for this study was also largely motivated by the availability of data and the authors' knowledge of these cities from work in earlier projects.

The period of investigation covers the year 1952, when cinema attendance was at historically high levels. ${ }^{8}$ Although the Second World War had resulted in severe economic repercussions on the lives of those caught up in the maelstrom, by 1950 most of Western Europe, supported by American initiatives such as the Bretton Woods monetary system, the Marshall Plan and the Truman Doctrine, had recovered from its immediate effects. ${ }^{9}$ Of course, Sweden was an exception, benefitting from its 
neutrality during the conflict. The economic growth that began in Sweden in 1930 continued intermittently throughout the Second World War. ${ }^{10}$ From 1950 to 1970, however, all three cities in our study, Antwerp, Gothenburg and Rotterdam, experienced unprecedented levels of economic expansion.

Antwerp was the largest city in Belgium and - in contrast to the rest of the city - its harbour survived the war relatively unharmed. This facilitated national economic growth, and the harbour grew to become the cargo port par excellence for Western Europe in the immediate post-war years. ${ }^{11}$ Rotterdam was the second largest city in the Netherlands, and remained so also after the war despite receiving severe damage during it. On 14 May 1940, a large part of the city centre was destroyed by German air bombardment and the ensuing fire. As with Antwerp, Rotterdam's harbour was to play a vital role in the economic recovery of the country. During the first decade after the war, priority was given to rebuilding port facilities, which deferred the recovery of the bombed city centre until the early 1950s. ${ }^{12}$ Indeed, it was not until the mid-1950s that cinema building took off. ${ }^{13}$ Gothenburg, like Rotterdam was the second largest city in Sweden, and like both Antwerp and Rotterdam, the city had large manufacturing industries and shipyards that ensured rapid economic expansion in the period following the Second World War. ${ }^{14}$

This study is based on datasets created within the frameworks of different research projects (for details, see the section 'Description of the dataset' below). For these data collections, the cinemas in each of the cities were identified, their locations mapped and film programming data were collected for the cinemas that advertised the public screenings of feature films in local daily newspapers. The programming data designates which film was screened in which cinema at which point in time. Our approach is data-driven, with information about the cinemas and their programming serving as starting points from which we test two methods of visualisations.

Faced with a lack of scholarly literature on film distribution and exhibition in cities in Europe in the 1950s, we use the 'run-zone-clearance system' and the practice of 'move-overs', associated with the distribution practices of major Hollywood companies in the classical period, as conceptual models to discuss our findings. Thus, in examining the flow of films through the cinemas in the three cities, we examine what the data-driven visualisations of cinemas and programming data can reveal about the programming practices of film exhibitors, and if there is any resemblance to the established practices developed by the Hollywood majors. In the following section, the nature of the American system of distribution is outlined, as well as an account of the presence of the major Hollywood studios in the 
three national markets featured in this study. This is followed by an account of our rationale for applying these particular methods, an explanation of our methods, and a description of the dataset.

\section{Organisation of distribution and exhibition: Hollywood in relation to Europe}

With Paramount Pictures, Adolph Zukor and William Hodkinson were the first in Hollywood to create a vertically integrated film company with control over all levels of the supply chain: film production, distribution and exhibition. This was in the early 1920s, and the other large studios soon followed suit. This made it difficult for the smaller companies involved in either production, distribution or exhibition to intervene. Paramount perfected a distribution system based on block booking and the run-zone-clearance system that would form the basis for standard industry practice in the US of the 1930s and 1940s. ${ }^{15}$

In 1938, a lawsuit was begun by the US Department of Justice against the vertically integrated Hollywood film studios. The suit was resolved in the Hollywood Antitrust Case of 1948, also known as the Paramount Act. The new legislation entailed a disintegration of the vertically integrated company structure, forcing the vertically integrated Hollywood companies to divest themselves of shares of their cinemas. ${ }^{16}$ Although the decree enacted a ban on block booking and the system of run-zone-clearance, they still remained largely in practice until the emergence of multi-screen venues and blockbusters in the 1960s and 1970s required different distributional strategies. ${ }^{17}$

The purpose of the block booking system had been to make the time and therefore costs of renting and letting films as efficient as possible for both producer and exhibitor. However, block booking was a thorn in the side of independent exhibitors, as it obliged them to rent a package of films rather than individual film titles of their choice. As Hanssen has shown, their complaints were not completely justified. There was room in the contracts for adaptation (e.g. cancellation clauses) and changes in the film titles. Exhibitors made use of this but to a lesser extent than had been possible, mainly because renting films individually was considered too time-consuming. ${ }^{18}$

The run-zone-clearance system prescribed that an exhibitor was given the exclusive right to screen a film in a delimited area ('zone') for an ordained period of time. Subsequently, the film disappeared from the market for some time ('clearance') and returned to another area for a consecutive 'run'. Accordingly, films premiered in cinemas with large seating capacities in the entertainment centres of the big cities (first-run), before they were distributed out to smaller 
cinemas in the same cities and then to the smaller satellite and rural towns. In addition, so-called 'move-over clauses' allowed the larger chains to keep the films within their circuits, because the license for a particular film would include all the cinemas of a circuit. This way, runs in different cinemas would be treated as a continuation of the run, not as a subsequent run (for which new stipulations had to be negotiated). ${ }^{19}$

In countries in Europe, the scale of film production and reach of distribution never came close to the levels experienced in the US during the interwar years. The organisation and size of the European film industries have varied considerably over time, due to political and economic changes and war. With a few exceptions, for example French companies in the early period, the German UFA group and some English-language films, production in European countries has catered largely to domestic markets. In two of the countries of our research, Belgium and the Netherlands, the separation between production on the one hand and distribution and exhibition on the other hand was much sharper than in the US. In contrast, Sweden has a long history of a centralised film industry with vertically integrated film companies. In the Netherlands and Belgium, the film production sector never really got off the ground, whereas in Sweden film production was more developed.

However, regardless of whether the scale of domestic production was significant, the competition from Hollywood in terms of film supply was overwhelming. This did not mean that the Hollywood companies also dominated the exhibition market: in the Netherlands, for example, the market was protected by the Netherlands Cinema Alliance, which kept a close eye on American interference. ${ }^{20}$ In Belgium, only Loew's MGM owned five theatres. ${ }^{21}$ According to the American film trade publication Film Daily Yearbook, in general, European cinemas were not owned by American studios. Rather, access was gained through the major studios' distribution channels. Despite its small size, Belgium in 1952 had ten American film studios represented in the country with local distribution offices: Paramount, RKO, Republic, 20th Century Fox, Warner Bros., Loew’s MGM, Universal, Selznick Releasing Organisation, United Artists and Columbia. The Netherlands boasted six: Paramount, RKO, Republic, 20th Century Fox, Warner Bros. and Loew's MGM. In Sweden, all the companies mentioned above had an office except the Selznick Releasing Organisation. ${ }^{22}$ Given the presence not only of Hollywood films on European screens but also of so many Hollywood distribution offices, the question arises as to whether (or to what extent) the run-zone-clearance system that had proven successful in the American market can be recognised in our sample of European cities. 


\section{The film market in Belgium, Sweden and the Netherlands}

There are considerable differences between the three film markets in our comparison, especially regarding the level of market integration, which was much higher in Sweden than in the Netherlands and Belgium. In the 1950s, the exhibition market in Belgium was highly fragmented and dominated by private investors, who operated only a few cinemas per (group of) exhibitor(s). Market concentration was low and occurred mainly in the form of horizontal concentration. Scant film production, in combination with large numbers of cinemas and high attendances, made Belgium a lucrative market for film imports after the Second World War, particularly from the US. Exact figures of the number of distributors and the national hierarchy of cities with regard to the distribution of films do not exist for 1952, yet case studies for the Flemish cities of Antwerp and Ghent suggest that films were exhibited in these cities according to an hierarchical pattern, opening in first-run (centre) cinemas, then moving to second-run and, later, subsequent-run (neighbourhood and district) cinemas. ${ }^{23}$

Swedish film production flourished in the post war period, despite being unsettled by state intervention in the form of a higher entertainment tax, a production strike in 1951 protesting tax raises, and government enforced price control of tickets. The expansion of the film industry led to the consolidation of three vertically integrated film companies: AB Svensk Filmindustri, Europa Film AB and Sandrews AB. The integrated companies controlled the industry's trade organisations and tightly regulated every form of competition. Located in the capital of Stockholm, they owned, co-owned or controlled two-thirds of the total exhibition capacity in the country, including the most profitable cinemas in Sweden's larger cities and key towns. A corporation comprising non-profit organisations with ties to the workers movement constituted a further vertically integrated corporate structure, through its ownership of the production company Svenska AB Nordisk Tonefilm and control of over 560 cinemas largely operating in multipurpose community venues but also in some cities such as Gothenburg. This organisation was not, however, as influential as the commercial companies that owned the key, profitable city cinemas. ${ }^{24}$

Finally, in the Netherlands, the distribution as well as the exhibition sectors were relatively fragmented. There was a degree of industrial concentration, mainly horizontal integration in the form of cinema chains. However, this took place on a small scale, with only three chains operating more than ten cinemas in 1948 - the regional chains Gofilex, Miedema and Hirschberg - which 
were all active outside of the larger cities, and a fourth chain run by the Van Royen family that included mostly neighbourhood cinemas in Amsterdam. Integration between distribution and exhibition did occur, but again, it was on a small scale. There were no less than forty-three distributors who served 505 cinemas in 1951. Of these distributors, eight had a clear relationship with thirty-two cinemas. For the most part, distributors formed close associations with one or two cinemas. ${ }^{25}$

The presence of the three major integrated companies in Sweden created a film market that differed considerably from that of Belgium and the Netherlands. In the two countries on the continent, the film markets were more-or-less fragmented, although cinema chains did exist to some degree. An examination of how films moved through the three different cities in our sample can serve as a point of departure to explore and compare the workings of the local exhibition markets.

\section{A mixed-method approach using visualisation tools: Maps, network visualisations and time-plot analyses}

Film screenings, as the focal point where films and audiences meet, are ephemeral by nature; they are historic events that are no longer there and can only be 'reconstructed' by relying on contextual information. ${ }^{26}$ In the wake of the digital turn in the humanities, the emergence of New Cinema History as a movement in film history has stimulated the collection, storage, presentation and analysis of large sets of contextual data related to film exhibition and distribution in digital form. ${ }^{27}$ A 'spatial turn' in film historical inquiry has led to increased scholarly attention to the spatiality of cinema and in particular to geo-visualisations of film screening venues. ${ }^{28}$ Our study is anchored in this academic context and involves three forms of visualisations for analysis: mapping, network analysis and time-plot analysis. The method of mapping is only briefly presented below, as this has been thoroughly discussed elsewhere. ${ }^{29}$ Network analysis, however, has been far from fully exploited as a tool to explore the circulation of films across space and time. ${ }^{30}$ For this reason, we offer a more detailed understanding of network analysis, beginning with a presentation of our precursors in the field. The section concludes with a description of the time-plot analysis, which was developed as a possible method for addressing the time lapses between the screenings of the same film in different cinemas. 


\section{Maps}

We plotted the geo-referenced cinema venues on historical maps dating from the period. The visualisation of the cinemas within the cities facilitates the analysis of the relationship between them, and their position in the geographical zones that are important to the run-zone system - city centre and more peripheral locations - as well as their distance to each other. Because the time of analysis in this study is in the beginning of the development of Western welfare societies, the boundaries of the cities are defined by the means of transportation available to the inhabitants: bicycle, train or tram. Cars had not yet had a strong impact on urban life.

\section{Network visualisation}

One means of historical exploration to capture the contexts of film exhibition is the examination of networks of people, venues and films. A first attempt to study local film exhibition networks and chain formation based on network analysis was performed in the late 1970s by Karel Dibbets. He studied the monopolisation process of theatre chains by examining the connections between them in the form of exhibitors' so-called 'double functions', based on the assumption that a person who occupies a leading position in two or more exhibition companies establishes a connection between these companies. Multiple connections then form a network, which in turn is an indication of economic concentration. ${ }^{31}$ Using the membership records of the Nederlandse Bioscoopbond (NBB, Netherlands Cinema Alliance), ${ }^{32}$ Dibbets created a dataset with the names of more than 1,200 exhibition companies, directors, managers and legal entities, as well as the names of 376 cities. Given the large amount of collected data, he decided to use computer-aided graph theory and analysis. With the subsequent analysis, Dibbets not only demonstrated substantial parallels in the structure of the exhibition sector prior to the Second World War II with that of the late 1970s in terms of size, geographical distribution and attendance, but also regarding the steady increase of industrial concentration in the sector. ${ }^{33}$

Decades later, members of the Kinomatics Project in Australia adopted network analysis as a method. Rather than using the visualisation tool to uncritically handle, measure and evaluate big data, members of the Kinomatics project used them to lay bare the dynamics of cultural exchange and, more particularly, the reciprocal exchange of films between countries. ${ }^{34}$ It is this reciprocal exchange of films between exhibitors - albeit in national contexts - which is also the focus of our study.

To analyse the flow of films between cinemas in each city, we performed a simple network visualisation with Gephi, a free, open-source software for network visualisation and analysis. ${ }^{35}$ 
In network analysis idiom, the cinemas are called 'nodes' and the links between the nodes (films moving from cinema A to B) are called 'edges'. The network is directional, meaning that the direction of the flow matters. We use the direction of the flow of films between cinemas to distinguish two main types of cinemas: 'first screening venues' and 'subsequent screening venues' ${ }^{36}$ Cinemas where films started their trajectory through the city are called 'first screening venues'. It should be noted that the first screening only refers to the first screening of a film in the specific period covered in this dataset. In other words, it might have been the case that a film was shown earlier in another cinema in the same town. As will become clear from the analysis, the 'first screening venues' were frequently premiere theatres, but this is not necessarily the case. Accordingly, cinemas that mainly screened films which had previously been screened elsewhere in the city are labelled 'subsequent screening venues'. This, however, is not a clear-cut distinction, as many cinemas would have had both first and subsequent screenings of the films that moved through the city. In the visualisations of the networks, we used the Fruchterman Reingold algorithm, as this creates a visualisation that positions nodes with strong edges close to each other. ${ }^{37}$ The size of the node represents the size of the cinema: the larger the node, the higher the seating capacity. We attempted two variations of the network visualisation: one that shows all movements of films between cinemas (edge weight 1, meaning that the minimum of 1 edge [connection] between nodes is shown) and one that only shows when eight or more films moved from one cinema to the other (edge weight 8). In our analyses, we focus on the second variation (weight 8), because it makes it easier to notice clusters of cinemas that shared films more extensively than others. It also allows us to identify isolates more clearly: cinemas that shared few films with others and so were less connected to the network as a whole. ${ }^{38}$

The network visualisations provide us with an empirical basis upon which to establish patterns of film movements between cinemas and thus allows us to point to relationships between cinemas based on their programming. One explanation for the existence of a relationship between cinemas could be shared ownership, horizontal integration or the (hidden) double functions of active exhibitors, but it could also point to a hierarchical relationship between a first run and a second (or consecutive) run cinema. The visualisations only show the flow of the films and not the title of a film, hence it is not known when more copies of one film circulated on the market and simultaneous screenings of the same film occurred. As this can be important in the analysis of the programming at a particular cinema and indicative of the relationship between cinemas, we complemented the visualisations with separate lists of simultaneous screenings. Another important aspect of the exhibition and flow of films that is lost in 
the network visualisations concerns the temporal dimension of the film flow. To capture this, we created a second kind of visualisation, a time-plot analysis.

\section{Time-plot visualisation}

The time-plot graphs present the screenings of individual films in all cinemas in a city on a timeline. This allows us to establish the period during which a film was screened in one cinema and the period between different runs of a film. As the dataset unfortunately does not contain information about the local distribution company of the films, but information on the film production company can readily be found via the Internet Movie Database (IMDb), we decided to create a sample consisting of recent films (produced in 1951 and 1952) by two Hollywood majors (Paramount and MGM) and two Hollywood minors (Columbia and Republic), which were screened in the respective cities in 1952. The additional data originates from the data archive produced by the European Cinema Audiences project and was collected following the same protocols. The reason for including films produced in 1951 and 1952 was to account for the time it took for the films to arrive in Europe. The samples of films by these four studios can show connections between cinemas or chains and particular production studios. We also developed this analysis of film flows to reveal patterns of periods of clearance in the life cycle of a film exhibited in a particular city.

\section{Description of the dataset}

The analysis presented here and the data collection on which it is based are the results of a partly project-based and partly informal collegial collaboration which includes scholars from several European countries. The research project European Cinema Audiences. Entangled Histories, Shared Memories is the liaising node for the collaboration. ${ }^{39}$ Although the European Cinema Audience project aims to compare the experiences of cinema-going in seven European cities in the 1950s (including Gothenburg and Rotterdam), the more informal collaboration presented here focuses on producing a harmonised data set of cinemas and programmes of feature films screened for public viewing in the year 1952 in the three selected European cities, and to explore methods of comparing film exhibition and distribution using this harmonised data set. The data set used for this article is available online, and a detailed presentation of the provenance of the aggregated data set and reflections on its potential use have been recorded in an accompanying data paper. ${ }^{40}$ 
The 'backbone' of the dataset is the daily screenings of feature films in cinemas that were advertised in the press. The key source for information on film screenings were newspaper listings and advertisements, mainly taken from: Gazet van Antwerpen, Göteborgs Handels- och Sjöfartstidning, Het Vrije Volk and De Telegraaf. Where possible, the film titles were identified (sometimes using additional information in the advertisements, such as names of directors or actors) and subsequently linked to a persistent identifier at IMDb. ${ }^{41}$ The dataset used here only contains information on feature films (longer than 50 minutes). Short films and newsreels were left out of our analysis, because these were announced only incidentally and unevenly in the press and are frequently difficult to identify. The fact that we have collected just one year of programming data (1952) to a certain extent handicaps the analysis of the film flow, because in the early 1950s, the life cycle of films could last well beyond one year/season. Nevertheless, the volume of films under scrutiny does allow for preliminary conclusions, which, of course, can be further investigated.

The dataset includes the programming information of a total of 99 cinemas. Cinemas were not included in the analysis if the data was too scarce (if less than ten screenings were known) or if the programming was only incidentally advertised. Table 1 shows the number and percentage of cinemas with programming information that were included in the dataset and the analysis. Rotterdam was the only city in which findings are based on a complete coverage of programming information. For all cinemas in all three cities the seating capacity was known, enabling us to compare the size and volume of the cinema markets.

We included cinemas in our selection if they were part of the urban cinema system of the larger agglomeration, which did not always neatly follow the boundaries of municipal jurisdictions. For the Rotterdam case, we also included two cinemas located in the neighbouring city of Schiedam, because they were an integral part of the moviegoing practice of Rotterdam inhabitants, as is demonstrated by the fact that Schiedam film programming was traditionally included in the Rotterdam film listings in local and national newspapers. Schiedam and Rotterdam were also closely knit via a shared public transportation system. In this article, all mentions of Rotterdam should therefore be read as 'Rotterdam and Schiedam', denoting a wider urban conglomeration. For Antwerp, we included cinemas that were located in neighbourhoods in and adjacent to the city centre (postal codes 2000, 2018, 2060) and the adjacent district of Borgerhout (2140). ${ }^{42}$ 


\begin{tabular}{|c|c|c|c|}
\hline City & Number of cinemas & $\begin{array}{l}\text { Number of cinemas with } \\
\text { programming info }\end{array}$ & $\begin{array}{c}\text { Number of cinemas seating } \\
\text { capacity known }\end{array}$ \\
\hline Antwerp & 46 & $31(67 \%)$ & 46 (100\%) \\
\hline Gothenburg & 40 & $30(76 \%)$ & 40 (100\%) \\
\hline Rotterdam & 13 & $13(100 \%)$ & 13 (100\%) \\
\hline
\end{tabular}

Table 1. Representativeness of the cinema set.

The network visualisations are based on the films that moved from one cinema to another in 1952. The films that were screened simultaneously in two or more cinemas are excluded from the network analysis and have been inventoried separately. We did not include the films that returned to the same cinema, as no relation is brought to light by doing so.

\section{Analysis}

\section{Introduction}

The basic statistics of the dataset reveal some structural differences between the cinema landscapes of the three cities under scrutiny, which are presented in the tables below (see Table 2 and 3).

Rotterdam is an obvious outlier, with the highest number of inhabitants and the lowest number of cinemas by far. This can be partly explained by the Second World War, when twelve of the nineteen cinemas were destroyed, amongst which were the largest premiere theatres. It was only in 1962 that the pre-war number of 19 cinemas was surpassed. ${ }^{44}$ However, a further explanation is the restrained development of Dutch cinema culture in general when compared to other European countries. ${ }^{45}$ Nevertheless, the average (777) as well as the median (743) size of the Rotterdam cinemas was high in terms of seating capacity. ${ }^{43}$ Gothenburg had many cinemas, but they were relatively small, as we can tell from the average (441) and the median (412). Gothenburg and Rotterdam had similar size ranges, from the smallest 150 (Gothenburg) and 184 (Rotterdam) to the biggest 1,048 (Gothenburg) and 1,241 (Rotterdam). Antwerp has the highest average (872) and median (800) values for seating capacity, with cinema sizes ranging from 280 to 2,000 seats. 


\begin{tabular}{|c|c|c|c|c|c|c|c|}
\hline City & Population & $\begin{array}{c}\text { Total } \\
\text { number of } \\
\text { cinemas }\end{array}$ & $\begin{array}{l}\text { Cinemas in } \\
\text { analysis } \\
\text { (nodes) }\end{array}$ & $\begin{array}{c}\text { Total } \\
\text { seating } \\
\text { capacity }\end{array}$ & $\begin{array}{l}\text { Average } \\
\text { seating } \\
\text { capacity }\end{array}$ & $\begin{array}{l}\text { Median } \\
\text { seating } \\
\text { capacity }\end{array}$ & $\begin{array}{c}\text { Inhabitants } \\
\text { per seat }\end{array}$ \\
\hline Antwerp & $\begin{array}{c}526,440 \\
(1950)\end{array}$ & 46 & 31 & 40,124 & 872 & 800 & 13 \\
\hline Gothenburg & $\begin{array}{c}353,580 \\
(1950)\end{array}$ & 40 & 30 & 17,640 & 441 & 412 & 20 \\
\hline Rotterdam & $\begin{array}{c}765,879^{43} \\
(1952)\end{array}$ & 13 & 13 & 10,104 & 777 & 743 & 76 \\
\hline
\end{tabular}

Table 2. Comparative statistics cinemas in the three cities in 1952.

\begin{tabular}{|c|c|c|c|c|c|c|c|c|}
\hline \multirow[t]{2}{*}{ City } & \multirow[t]{2}{*}{$\begin{array}{l}\text { Unique } \\
\text { films }\end{array}$} & \multirow[t]{2}{*}{ Screenings } & \multicolumn{2}{|c|}{$\begin{array}{l}\text { ‘Moving' films } \\
\text { (edges) }\end{array}$} & \multicolumn{2}{|c|}{$\begin{array}{l}\text { Films with } \\
\text { simultaneous } 1 \text { st } \\
\text { runs }\end{array}$} & \multicolumn{2}{|c|}{$\begin{array}{l}\text { Lifecycle: } \\
\text { number of } \\
\text { screening } \\
\text { days per film }\end{array}$} \\
\hline & & & absolute & $\begin{array}{c}\text { as \% of } \\
\text { number of } \\
\text { unique films }\end{array}$ & absolute & $\begin{array}{l}\text { as \% of } \\
\text { unique } \\
\text { films }\end{array}$ & mean & std \\
\hline Antwerp & 785 & 10,395 & 187 & $24 \%$ & 17 & $2 \%$ & 8 & 11 \\
\hline $\begin{array}{l}\text { Gothen- } \\
\text { burg }\end{array}$ & 800 & 21,355 & 268 & $34 \%$ & 108 & $14 \%$ & 15 & 56 \\
\hline Rotterdam & 444 & 4,568 & 48 & $11 \%$ & 24 & $5 \%$ & 7 & 12 \\
\hline
\end{tabular}

Table 3. Comparative statistics of film screenings in the three cities in 1952.

From the comparative statistics of the films we can tell that there is a contrast between the 'lifecycle' of films - the number of days that a film was screened in a city - of Gothenburg and that of the other two cities. In Antwerp and Rotterdam, on average, films would be screened for about one week, whereas in Gothenburg the average screening time for a film was two weeks. The high number of screenings in Gothenburg might be explained by the fact that the cinemas were relatively smaller in size, meaning it took longer to cater to the available audiences. 
Another remarkable point is the fact that even if in Rotterdam a comparatively low number of films was screened overall, the number of 'moving films' is very low (11\%). In the other cities, between $24 \%$ and $34 \%$ of all titles 'move', meaning they are screened in a second cinema within the year. This variance can possibly be explained by the low number of cinemas in Rotterdam - there were simply insufficient screens. The table suggests a strong association between the number of cinemas, the number of unique films and the number of moving films. However, the small number of moving films in Rotterdam is also likely to relate to the low average number of cinema visits (eight) per year. ${ }^{47}$ For the most part, there simply might not have been sufficient demand for an extended life of a film in another cinema.

The extremely high number of simultaneous first run screenings in more than one cinema in Gothenburg might, at first glance, suggest non-exclusivity contracts between distributors and exhibitors and hence a fierce competition between cinemas. However, as is explained below, the screenings of first run films in more than one cinema in Gothenburg generally took place in venues within a chain owned by the same exhibitor. Thus, the profits from first run screenings could be maximised and perhaps compensate for the relatively small size of the venues. A closer inspection of the companies involved will shed further light on this in the analysis of the networks.

\section{Antwerp}

In the post-war period, Antwerp's exhibition sector recovered quite quickly from the consequences of the war (damaged buildings as well as organisational principles imposed by the German occupier). The cinema sector was geographically dispersed across the city. The highest concentration of cinemas was to be found in the area close to the city's main train station, the Station Quarter. By 1952, the city of Antwerp and its adjacent district of Borgerhout accommodated a total of 46 active cinemas, for which we have the programmes of 31 (Table 1), operated by approximately thirty exhibitors.

Most exhibitors operated one cinema, but six groups of exhibitors operated more. The group with the most cinemas by far was what became known as the Rex cinema group, managed by Georges Heylen, who operated fifteen active cinemas in Antwerp in 1952. Although he became involved in the cinema business via his family-in-law as manager of the prestigious cinema Rex before the Second World War, his career progressed rapidly after the war. In contrast, other (groups of) exhibitors were long established in Antwerp's exhibition sector but, compared to Heylen, operated less cinemas in the 


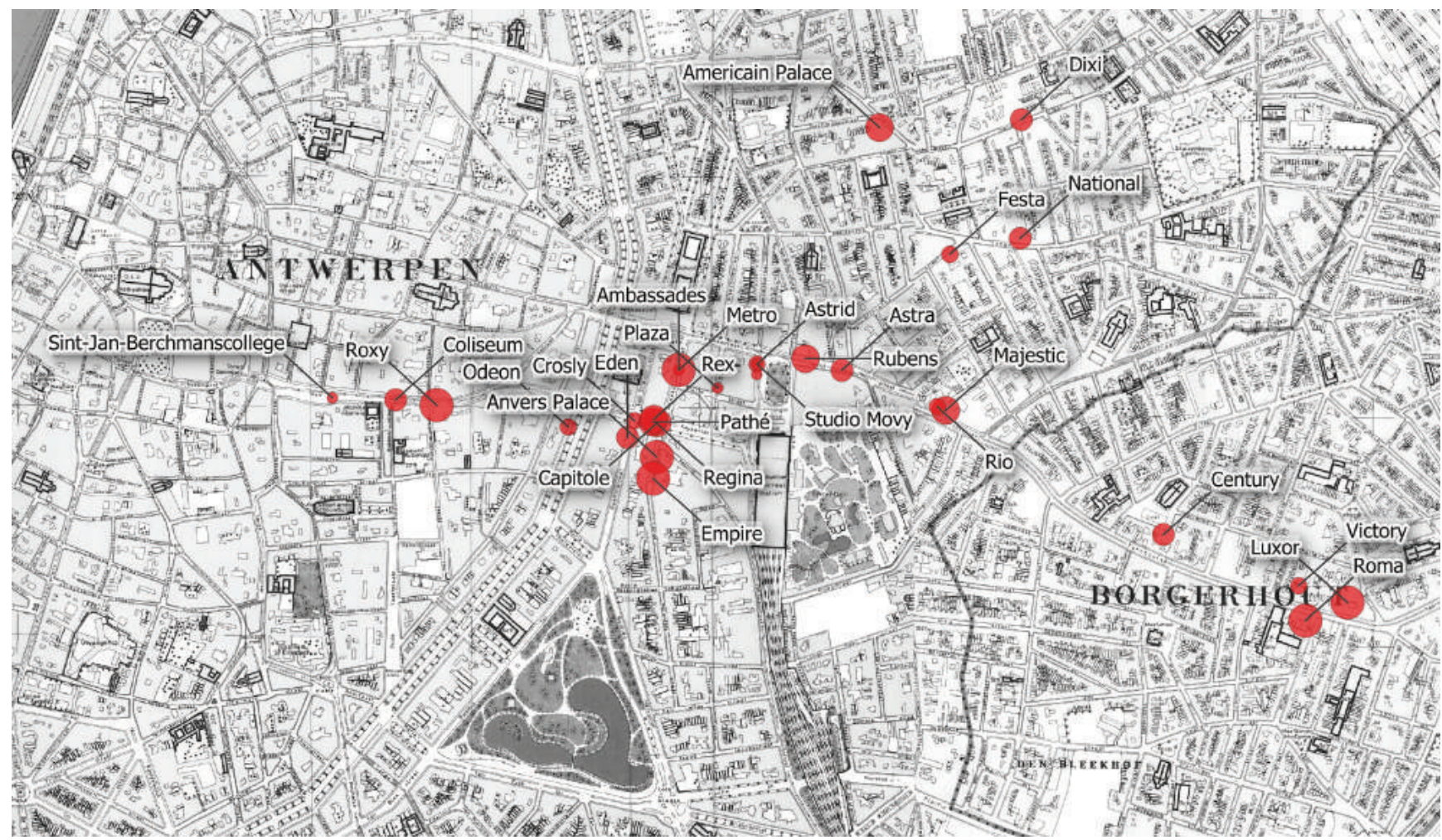

Figure 1. Map of Antwerp, showing the location of the cinemas included in the programming analysis. The size of the dots refers to the relative size of the cinema as measured by its seating capacity. Map: FelixArchief/stadsarchief Antwerpen, 1963: Ministerie van Openbare Werken (1:5000), inventory nr. BE SA 312291.

early 1950s. The Alkema/Bastiaenssens/Bekens group, for example, had six cinemas, amongst which was the prestigious cinema Rubens. The Cobelciné and NV Gerex/Hendrickx groups both operated four cinemas, and the Tyck/Gommers/Meerman and Spanoghe/De Paep groups three each. Like Heylen, all of these exhibitors operated both city centre and neighbourhood cinemas. ${ }^{48}$

An examination of the networks of the cinemas that shared at least one film (see Figure 2 below) and eight films or more (Figure 3) provides us with insights into the ways in which films moved from cinema to cinema. Three aspects can be examined: the number of cinemas with which one cinema shared films (represented by the number of arrows); the number of films shared between cinemas (represented by the thickness of the arrows); and the direction in which films moved between cinemas (represented by the direction of the arrows). The positioning of the nodes is not related to their geographical location in any way, but is determined by the Fruchterman Reingold algorithm used for this visualisation. 


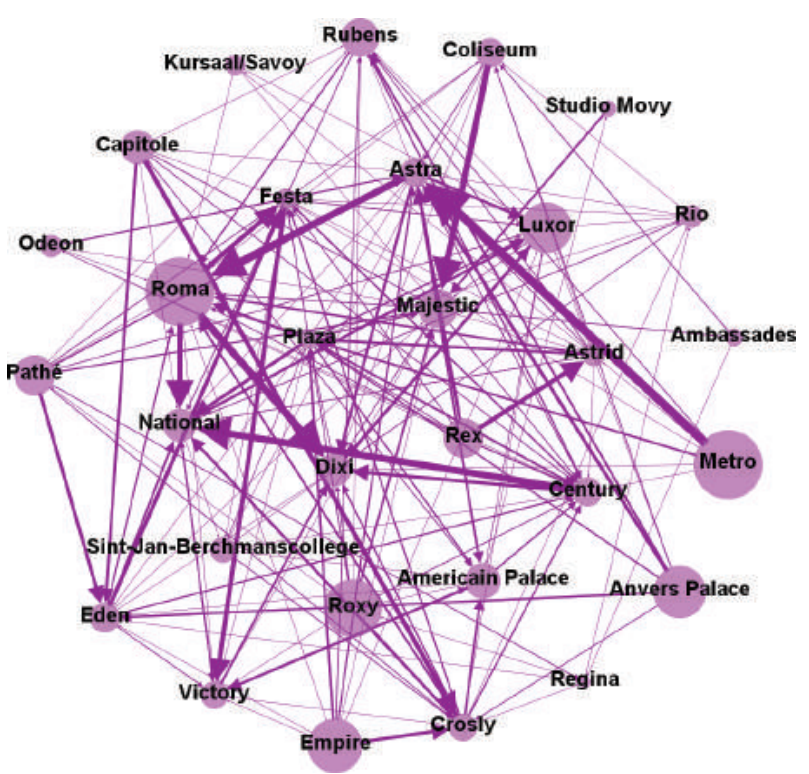

Figure 2. Flow of films for the Antwerp dataset, edge weight 1.

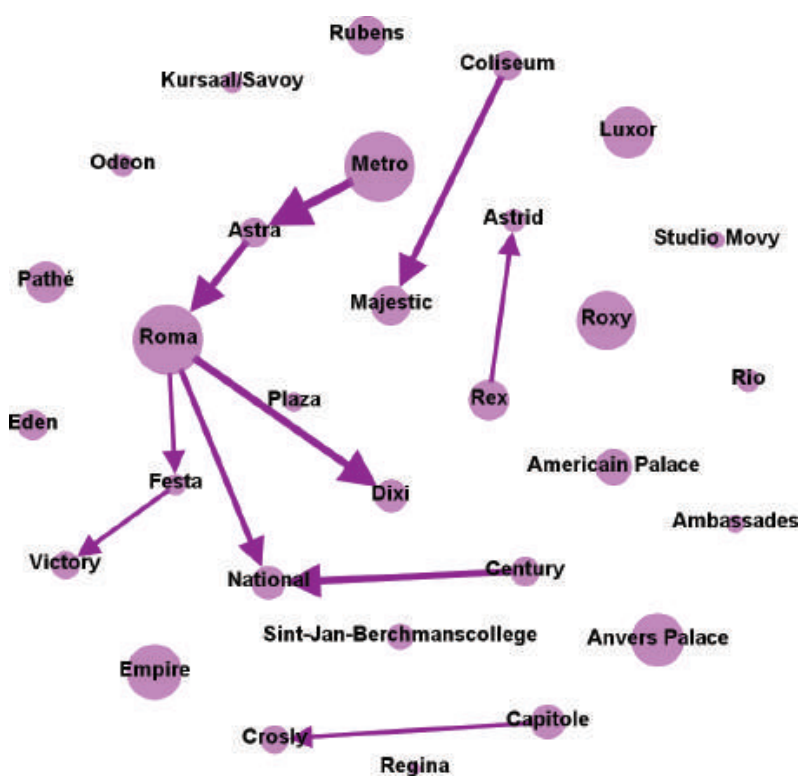

Figure 3. Flow of films for the Antwerp dataset, edge weight 8.

The clearest cluster of cinemas centres around Roma: as a central node it is connected to nearly all cinemas in the sample. Operated by Heylen, Roma was a neighbourhood cinema and had a capacity of 2,000 seats, which made it the largest cinema in the sample next to centre cinema Metro (also 2,000 seats). Located in close vicinity to the Station Quarter, it served as a pass-through 
from the centre cinemas to other neighbourhood cinemas: Figure 2 shows that it served as a 'first screening venue' as well as a 'subsequent screening venue'. With the exception of cinema Astra, all of the cinemas that showed films before Roma were centre cinemas operated by different exhibitors and located in or at the rim of the Station Quarter. The thinness of the corresponding arrows (representing the number of shared films) in combination with the large number of cinemas suggests that these subsequent screenings in Roma were incidental. In comparison, the thickness of the arrows indicating Roma as a 'first screening venue' amongst other neighbourhood cinemas is much more distinct. As Figure 3 shows, the neighbourhood cinemas Dixi, National and Festa in particular screened films after Roma on a more regular basis.

In relation to cinema Astra, however, Roma should be regarded as a 'subsequent screening venue'. This is remarkable, as Astra had a far smaller capacity (800) than Roma. It was located at the rim of the Station Quarter and functioned as Heylen's second-run cinema. Figure 3 not only shows a strong link between Astra and Roma, but an even a stronger connection with centre cinema Metro. Opened by MGM in 1949 in the same building complex as Heylen's flagship cinema Rex, Metro was the only cinema in Antwerp that was operated by a Hollywood major. The fact that films that screened in Metro were predominantly taken up by Heylen's cinema Astra not only indicates the strong ties between the American major and Antwerp's dominant exhibitor at the time but also foreshadows his takeover of Metro in the late 1950s.

Like Metro, the city centre cinemas Empire, Anvers Palace, Ambassades, Rex and Capitole acted solely as 'first screening venues', coinciding with their status as first-run cinemas. Empire, Anvers Palace and Ambassades are represented as isolates in Figure 3. This means that they shared films with any of the other cinemas on a less structural basis than Metro, Rex and Capitole. The strong connection between Rex and Astrid can be explained by the fact that they belonged to the same exhibitor (Heylen), who used Astrid as a second-run outlet for the films that premiered in his flagship-cinema Rex. Ownership could also be the reason for the considerable amount of shared films between Coliseum and Majestic. They both belonged to Leo Hendrickx, a long-established local exhibitor and chairman of the Syndicate Chamber of Antwerp of Cinemas and Subsidiaries, the local trade organisation that represented the interests of exhibitors.

However, ownership was not the only determining factor for the extent of shared films between cinemas. Capitole and Crosly belonged to different exhibitors: Capitole (950 seats) was operated by the Cobelciné group, which also managed the city centre cinemas Ambassades and 
Regina, as well as neighbourhood cinema Cameo. Crosly (760 seats) was operated by Payeur, an exhibitor with only one cinema in Antwerp at that time. In addition, as Figure 2 shows, other centre cinemas that belonged to the same groups of exhibitors did not share as many films as might be expected (Ambassades, Capitole, Regina were operated by the Cobelcine group; Anvers, Eden, Pathé by the Tyck/Gommers/Mermans group; Roxy and Empire by Spanoghe/De Paep). This is quite surprising, as one would expect that cinemas belonging to a chain would exchange more films than cinemas operated by exhibitors with only one cinema in the city: following the logic of the runzone-clearance model, an exhibitor with several outlets would want to bring back a successful title to a lower-ranking cinema within the cinema chain.

These exhibitors were in direct competition with one another to attract audiences. Unlike Heylen, who operated far more - and different types of - cinemas, they lacked the outlets to maximise the profits from successful films after their initial run. Although there may well have been a standard pattern of diffusion according to the run-zone-clearance logic, only Heylen controlled a sufficient amount of cinemas to operationalise it: the direction in which films flow along the (Metro-) Astra-Roma-National axis in Figure 3 illustrates this.

This lineage is also a clear example of how films generally moved from centre to neighbourhood cinemas, which is consistent with the logic of the run-zone-clearance system: films were launched in the (often larger) centre cinemas, then travelled to smaller centre cinemas. This can be seen in Figure 3, which shows the move of films from MGM's premiere cinema Metro to Heylen's second-run cinema Astra, and from Capitole to Crosly, as well from Heylen's first-run cinema Rex to Astrid. To a lesser extent (concerning the number of films) this is also visible in Figure 2, from first-run cinema Anvers Palace to Eden and Coliseum, and from first-run cinema Pathé to Eden.

Whereas capacity seems to play a decisive role in the trajectory of films within the centre, the same is not true beyond the city centre. Even when we consider the fact that a number of cinemas in other districts are not included in the programming analysis, Figure 3 shows that films regularly moved from smaller to larger neighbourhood cinemas (from Festa to Victory and from Century to National). The high cinema density that marked Antwerp's exhibition market in the 1950s, in combination with a strong key player (Heylen), could explain this degree of flexibility.

Although the graphs do not enable detailed conclusions on the trajectories of specific films, they do show that films mostly moved from Heylen's centre cinemas to competing centre cinemas, but never the other way around..$^{49}$ This could be seen as an indicator of his growing power as a local 
exhibitor in the city, as could the strong edges amongst his cinemas: although in 1952 he did not yet possess the majority of centre cinemas in the local market, he did operate the highest number of neighbourhood cinemas, which he could use to circulate his films for longer periods and, presumably, maximise profits. This not only strengthened his bargaining position with the major distributors but also provided him with the capital to invest in takeovers of most of his competitors' centre cinemas in the decade to come. ${ }^{50}$ The time plot analysis below supports this argument from a different angle.

\section{Time plots}

In a second phase of our analysis, the films that were screened in Antwerp cinemas in 1952 and produced in 1951 and 1952 by two majors (MGM and Paramount) and two minors (Columbia and Republic) were plotted on a timeline (Figures 4, 5, 6 and 7). Although the number of films included here is low, the time plots reveal patterns in relation to clearances between runs for the majors and minors included as well as their connections with the local exhibitors.

On the one hand, the time plots add to the network visualisations discussed above by revealing a certain degree of collaboration between groups of exhibitors competing with Heylen as the dominant exhibitor in the city at that time. On the other hand, they also show closer ties between the majors with long-established exhibitors such as the Tyck/Gommers/Mermans and Spanoghe/De Paep group, thereby isolating 'newcomer' Heylen.

Of the four Hollywood studios included in this time plot analysis, the number of MGM films is considerably higher than those of the others (38, compared with 28 by Paramount, 27 by Columbia and 7 by Republic). As addressed above, MGM was the only major who operated a film theatre in Antwerp and this most likely explains their prominence on Antwerp screens and, more particularly, in the MGM operated Metro. In addition, Figure 4 also shows that, with the exception of Anvers Palace (marked orange), Rubens (purple), Plaza (golden red) and Empire (dark red), all cinemas that screened the recent MGM films belonged to Heylen’s cinema group. This again emphasises the strong connection between MGM and Heylen that also emerged in the network analysis.

In contrast with MGM, there are no clear signs of exclusivity contracts between the other three producers and one particular (group of) exhibitor(s). With regard to the other Hollywood studios examined here, different films from the same producer were launched in cinemas of different (groups of) exhibitor(s), all competing with Heylen. For example, films from Columbia would be screened for first run in Roxy and Empire, operated by Spanoghe/De Paep, as well as Anvers Palace 


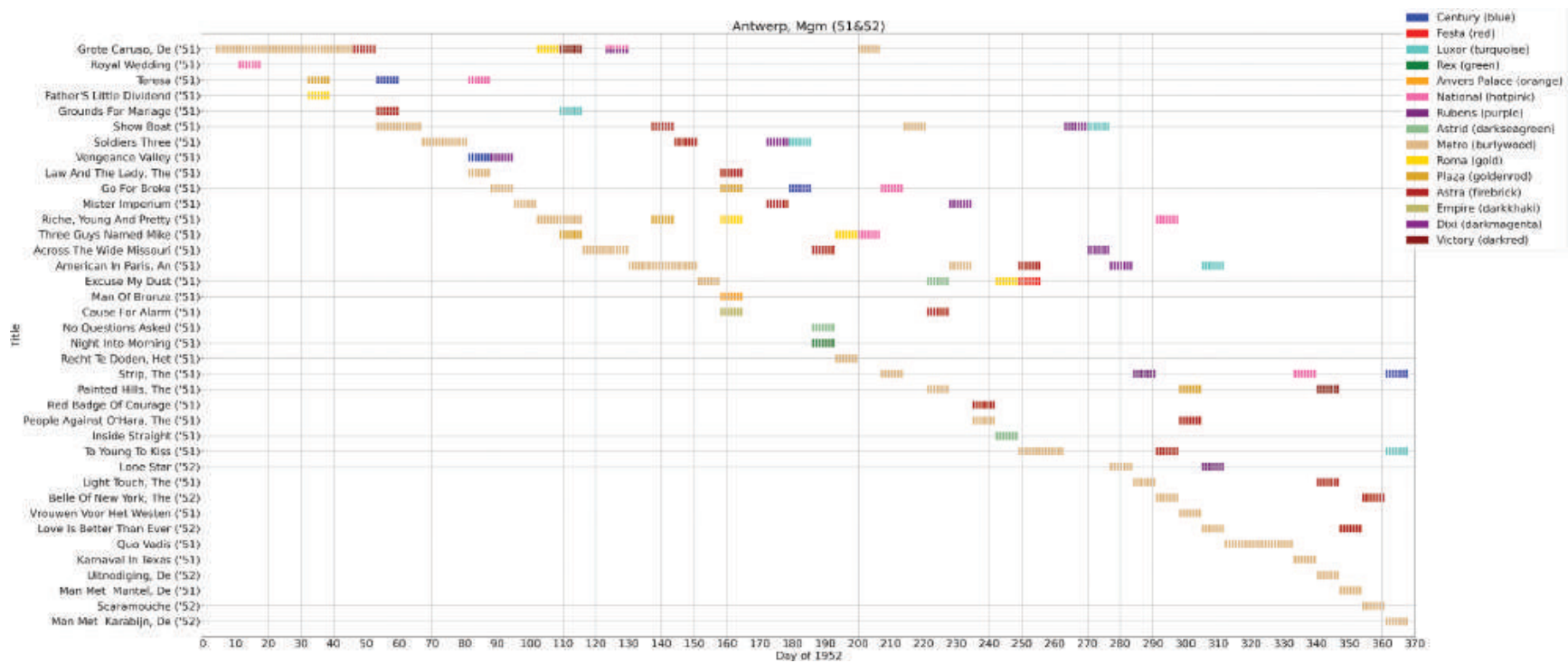

Figure 4. Time plot visualisation for all films produced by MGM in 1951 and 1952 that screened in Antwerp cinemas in 1952. The X-axis represents the number of days that a film screened, starting with the first day in 1952 that a screening was documented for cinemas in Antwerp.

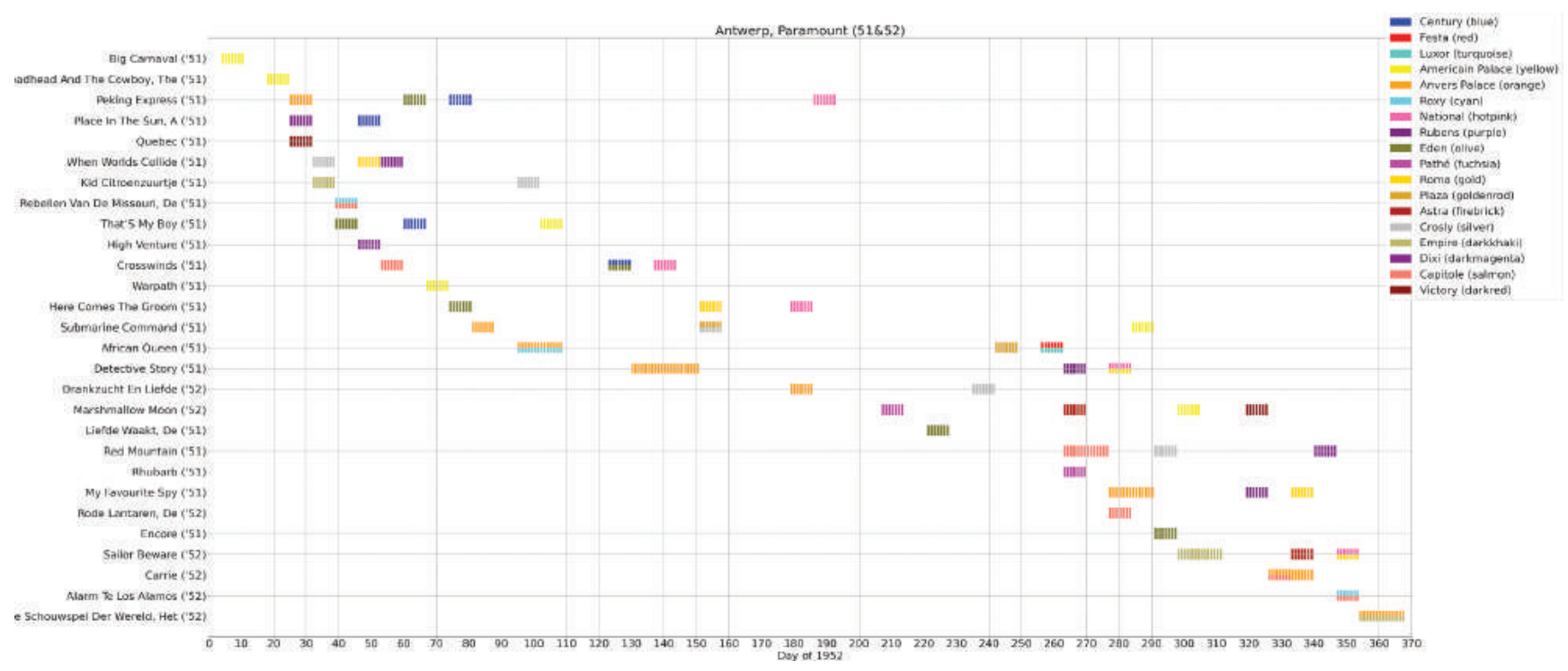

Figure 5. Time plot visualisation for all films produced by Paramount in 1951 and 1952 that screened in Antwerp cinemas in 1952. 
TMG $23(1 / 2) 2020$

Clara Pafort-Overduin, Kathleen Lotze, Åsa Fernudd and Thunnis van Oort

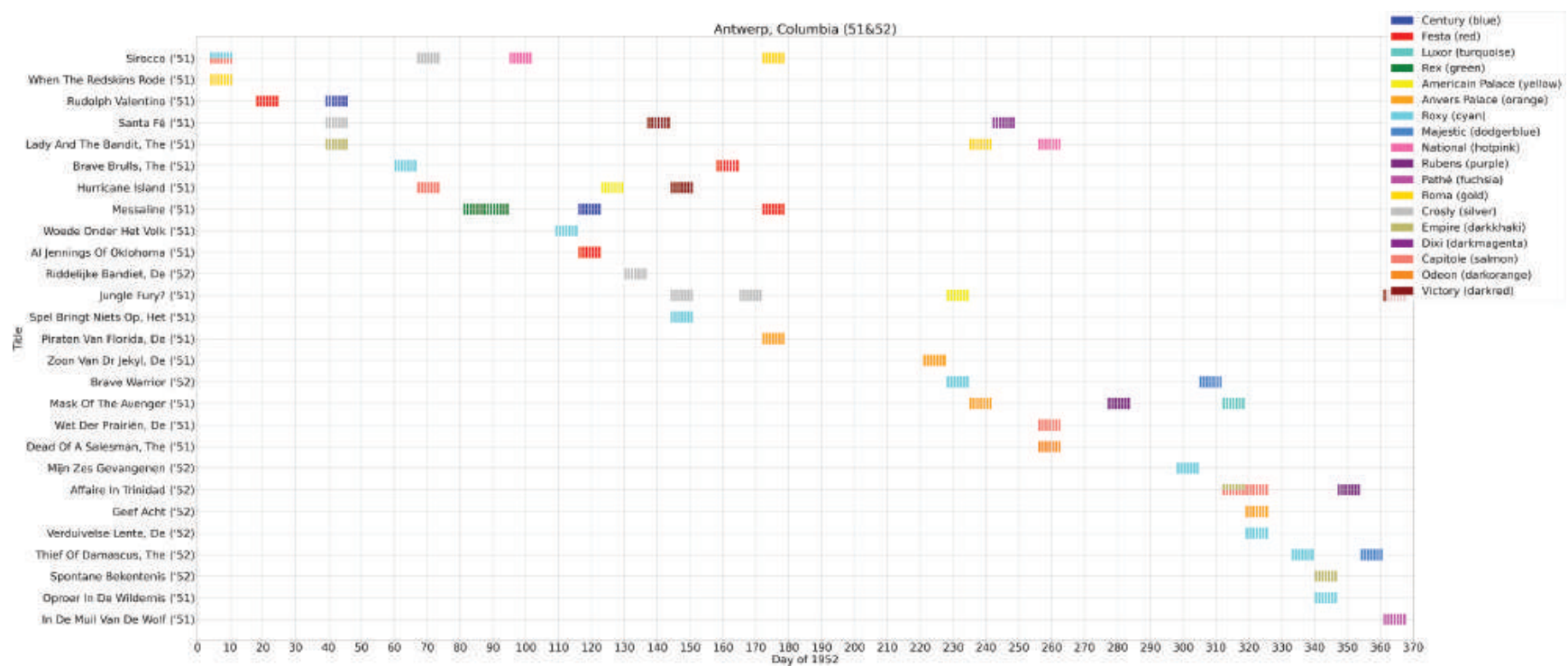

Figure 6. Time plot visualisation for all films produced by Columbia in 1951 and 1952 that screened in Antwerp cinemas in 1952.

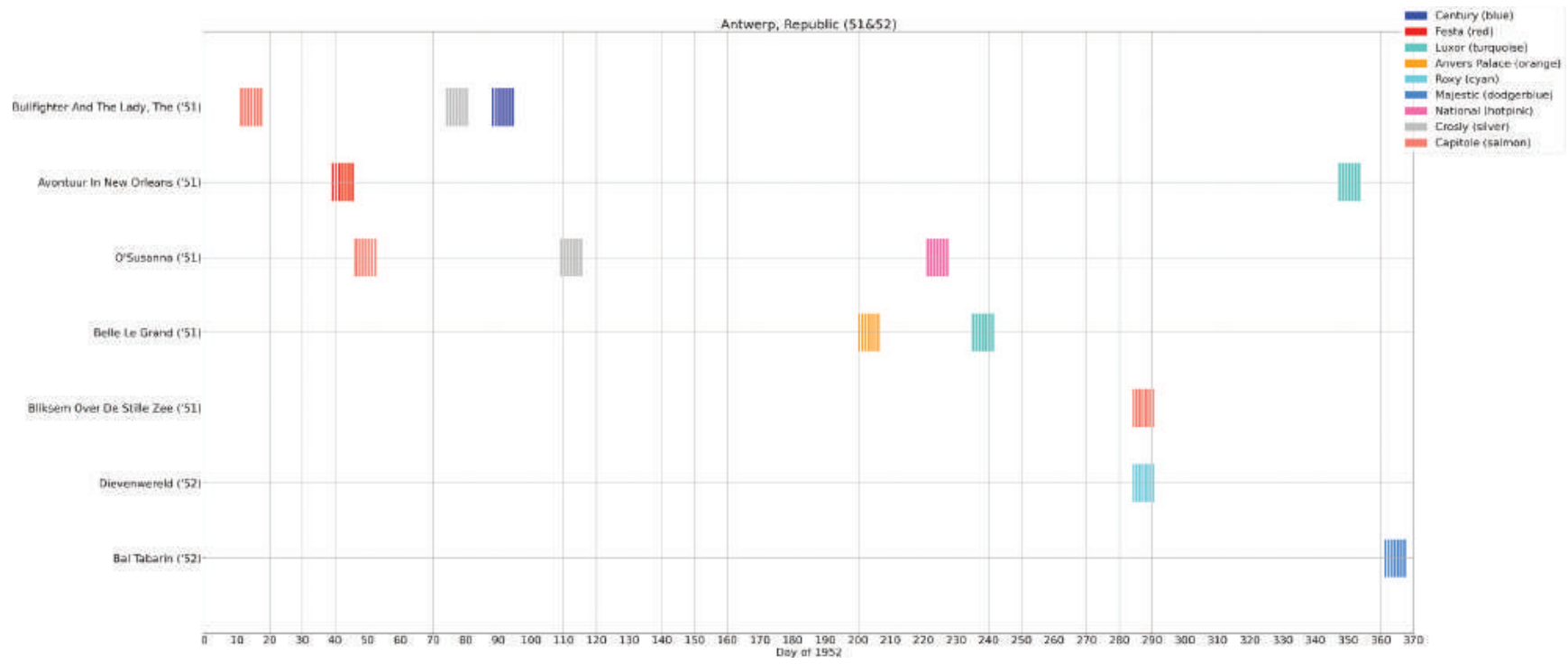

Figure 7. Time plot visualisation for all films produced by Republic in 1951 and 1952 that screened in Antwerp cinemas in 1952 
and Pathé, operated by Tyck/Gommers/Mermans (Figure 6). Films from Paramount were also strongly represented in cinemas of the Tyck/Gommers/Mermans group but were also launched in Capitole, which was operated by members of the Cobelciné group (Figure 5).

When we compare in more detail how the most recent films of the four studios were circulated in Antwerp, some patterns emerge. Films produced by MGM usually premiered in the studio's own cinema Metro for one to two weeks and often moved to the second-run cinema Astra with a clearance window of between four to nine weeks, followed by subsequent runs in Heylen's neighbourhood cinemas or, incidentally, centre cinemas that were competing with Heylen (Plaza, Rubens, Anvers Palace). In comparison with MGM, the patterns for Paramount and Columbia are less pronounced, which can be attributed to the apparent lack of exclusive contracts, but could also be the consequence of missing data for cinemas in Antwerp neighbourhoods and districts that were left out of this analysis. Nevertheless, the general differences between the number and length of the clearance windows of MGM on the one hand, and Paramount, Columbia and Republic on the other, suggest that different strategies were adopted by the different studios, rather than a uniform approach of film supply in this European city.

\section{Gothenburg}

A large share of the cinemas in Gothenburg was owned by vertically integrated film companies. ${ }^{51}$ Cosmorama $\mathrm{AB}$ was the largest company, with ten cinemas (Cosmorama, Flamman, Kaparen, Kronan, Nya Teatern, Odéon, Redbergsgården, Röda Lyktan, Spegeln, Victoria) in central locations as well as in the outskirts of the city. ${ }^{52}$ Cosmorama $\mathrm{AB}$ was a subsidiary of $\mathrm{AB}$ Svensk Filmindustri, the largest vertically integrated film company in Sweden, owning 95 cinemas in key cities and towns in 1950.53 The second largest cinema chain in Gothenburg was Royal Film AB, a company that was not formally a subsidiary company to a larger firm, yet two of its three owners also owned large shares in companies within the vertically integrated Sandrews Corporation, which presided over a chain of 36 cinemas in Sweden in $1950 .{ }^{54}$ Royal Film AB had five cinemas in Gothenburg (Capitol, Facklan, Mignon, Plaza, Royal). ${ }^{55}$ Biograf $A B$ Centrum was also part of a vertically integrated structure. Centrum cooperated with the film producing company Nordisk Tonefilm, which was part-owned by the distribution and exhibition company, Sveriges Folkbiografer. ${ }^{56}$ Biograf AB Centrum owned six cinemas in the city (Aveny, Göta, Lillan, Lorensbergs Bio, Saga, Skansen). ${ }^{57}$ Two more chains were active in Gothenburg in 1952, both locally based enterprises: Fastighets AB Orion (Carolus, Fyren, Palladium, Rialto, Röda Sten) and 


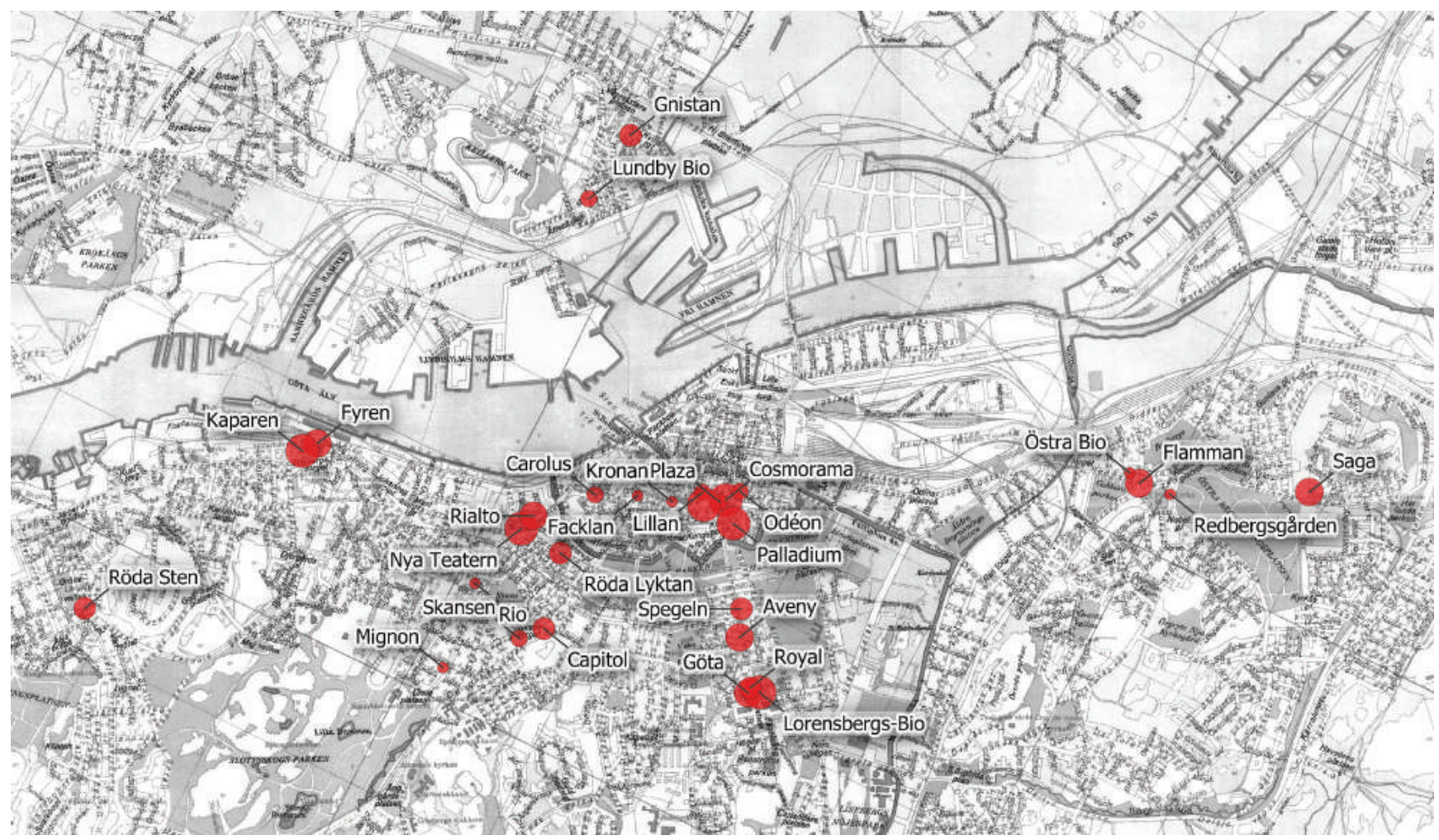

Figure 8. Map of Gothenburg, showing the location of the cinemas included in the programming analysis. The size of the dots refers to the relative size of the cinema as measured by its seating capacity. The map is based on a Gothenburg tourist map from 1951, produced by the City Planning Authority of Gothenburg.

Rune Engelbrektsson (Boulevard, Lundby Bio, Gnistan). Seven cinemas (Biorama, Olympia, Rex, Rio, Svea, Stjärnan, Östra Bio), were single-owned, small exhibition venues of around 200-300 seats. With the exception of Biorama, they were located in the periphery of the city and were typical neighbourhood cinemas showing older films and re-runs. ${ }^{58}$

Finally, Gothenburg also had cinemas which were operated by military units stationed in the city. Records held by the organisation for cinema owners reveal that in 1947, one garrison cinema in Gothenburg offered public exhibitions of feature films one to three days per week. In the 1955/56 season, four military cinemas were in operation. ${ }^{59}$ As they did not advertise, the military cinemas and a number of smaller cinemas (Biorama, Olympia, Rex, Svea, Stjärnan) were excluded from the analysis. Boulevard was also left out on the grounds that the cinema screened newsreels only.

Figure 9 illustrates the flow of films that moved between the cinemas in Gothenburg in 1952 that advertised regularly in the daily paper. The visualisation reveals complicated patterns of differences 


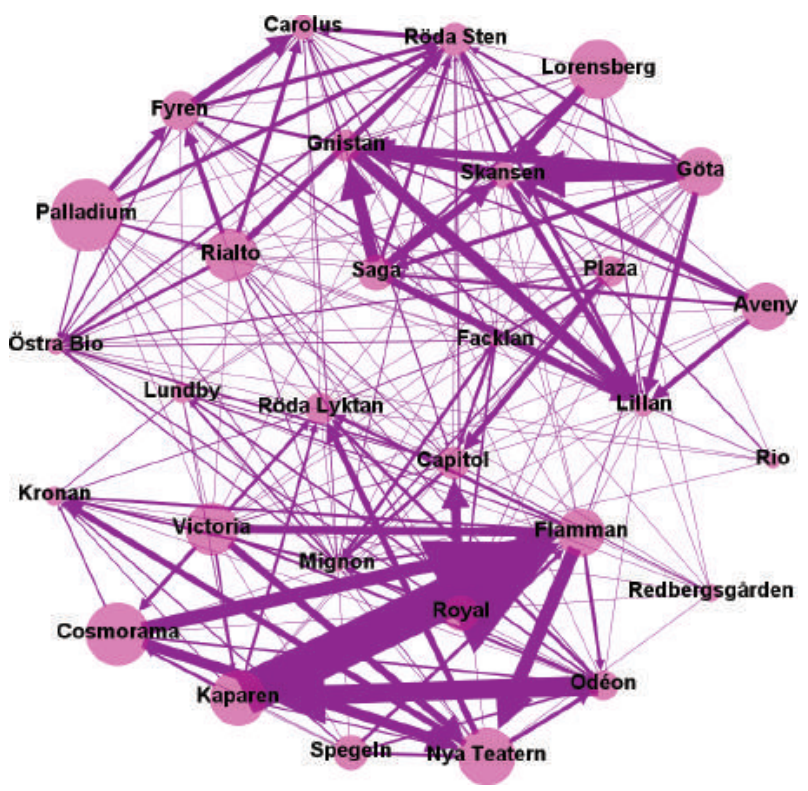

Figure 9. Flow of films for the Gothenburg dataset, edge weight 1.

regarding the number of cinemas with which any one cinema shared films. Kaparen clearly stands out with its extremely thick edge connecting it with Flamman; indicating also the direction of the film flow as moving from Kaparen to Flamman. Kaparen also screened a relatively large set of films after Odéon. All three cinemas were part of the Cosmorama chain.

The visual analysis of a threshold of at least eight edges (Figure 10), shows four clusters and six isolates. The four clusters correspond to the four larger cinema chains operating in Gothenburg at the time. Within the clusters it is possible to identify nodes that are first screening venues of films, indicative of first-run cinemas. In the Cosmorama chain, Victoria, Cosmorama and Odéon have this quality. Cosmorama and Victoria were old, lavish and - in the local context - large cinemas with more than 700 seats, situated in the city centre. Both cinemas sent films to the second-run cinemas Flamman and Nya Teatern, also part of the Cosmorama chain. Flamman is located in a neighbourhood in the periphery of the city to the east. Redbergsgården and Östra Bio are in turn located near Flamman - both are represented as isolates in the diagram. Redbergsgården, also a Cosmorama chain cinema, only exhibited films on weekends. ${ }^{60}$

Odéon was located in the city centre but, with its 500 seats, it was smaller than the other firstrun cinemas in the chain. Odéon sent films only to Kaparen. Kaparen opened with 800 seats in 1940 


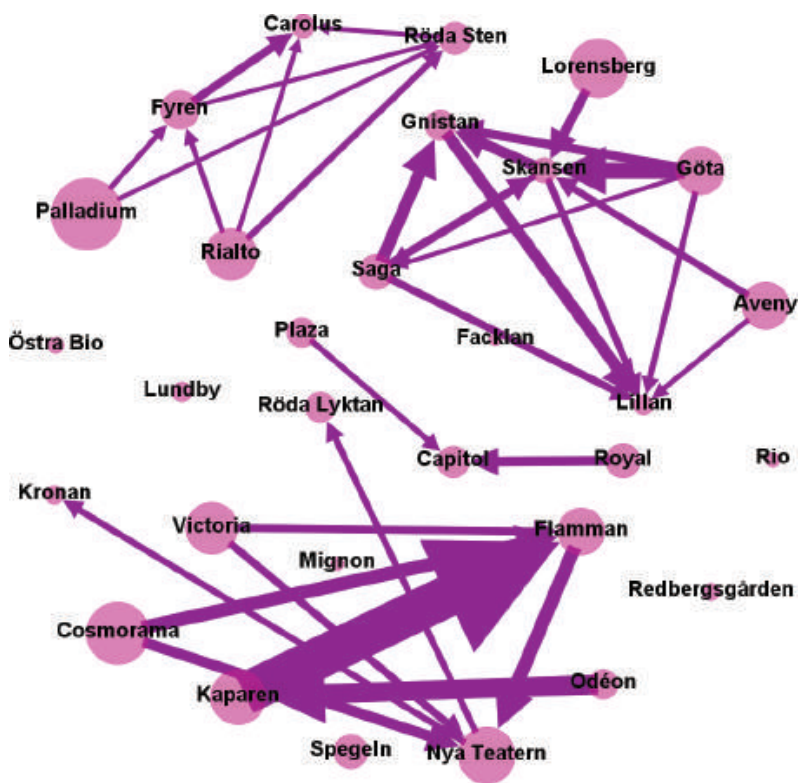

Figure 10. Flow of films for the Gothenburg dataset, edge weight 8.

at Stigbergstorget, a marketplace and transportation hub in a neighbourhood in the outskirts of the city to the west. The list of simultaneous runs reveals that a large number of films were shown at Cosmorama and Victoria, whereas a parallel screening took place at Kaparen. Cosmorama and Kaparen shared no less than 19 simultaneous film screenings in 1952; Victoria and Kaparen, 13. This analysis of film flows and simultaneous runs suggests that Cosmorama, Victoria and Odéon were inner-city, first-run cinemas and that Kaparen filled a similar function in a slightly off-centre city location. Kaparen offered first-run films in parallel exhibition with Cosmorama and Victoria; it also screened films after Odéon, exhibiting these films in the second-run in a different location in the city. As mentioned earlier, a significant number of films moved over from Kaparen to Flamman, located at yet another end of the city.

Two cinemas appear as subsequent screening venues within the Cosmorama chain, Röda Lyktan and Kronan, both located in the town centre. Röda Lyktan's seat capacity was approximately 400 and it had only one projector. A feature film screening would therefore require at least two intermissions. ${ }^{61}$ Kronan was one of the oldest cinemas in town; it was small and had not been properly renovated nor refurbished to meet the post-war audience's expectations of comfort. ${ }^{62}$ 
A clearer hierarchy of cinemas is discernible in the Royal Films cluster of cinema nodes. Plaza and Royal, both centrally located cinemas with around 400-500 seats, were first-run cinemas in their capacity as first screening venues. Both screened the films before they were shown in Capitol, which was located in an off-centre neighbourhood area. The chain also included the smaller cinemas Mignon and Facklan, which are isolates in the diagram.

Fastighets AB Orion also had two first-run cinemas, Palladium and Rialto, located in the city centre. Palladium was an old, prestigious cinema with over a thousand seats, and Rialto was not as lavish yet had a seating capacity of more than 800 . The chain included three other venues that were second-run cinemas and possibly third-run outlets. Röda Sten and Fyren were both situated west of the city centre in newly built neighbourhoods. Both Röda Sten and Fyren screened films after Palladium and Rialto. Furthermore, Röda Sten screened 18 films simultaneously with Palladium and Rialto. In relation to Carolus, both Röda Sten and Fyren were first screening venues.

In the Biograf $\mathrm{AB}$ Centrum chain cluster, Göta, Aveny and Lorensberg, fairly large cinemas (between 600 and 856 seats) were located near the city centre and rank as first-run cinemas. The others, Lillan (small), Saga (located far from the city centre) and Skansen (smaller cinema in an offcentre location), can be characterised as subsequent screening venues. At the same time, the direction of the films shown in Skansen as well as in Saga shows a two-way traffic. In other words, both cinemas functioned as both first and subsequent screening venue to each other. In relation to Lillan, they can both be characterised as first screening venues. Lillan, clearly, was a subsequent screening venue, as it screened films from no less than five cinemas in the city after they had been shown there. In this cinema cluster, Saga stands out as a cinema used for parallel exhibition, probably due to its distance from the city centre as well as from other competing cinemas. As many as 13 films were screened simultaneously at Saga and either Göta or Aveny.

Gnistan was a sibling cinema to Boulevard and Lundby in Engelbrektson's small chain. Gnistan was located across the river close to Lundby and was co-owned by Engelbrektsson and the Centrum cinema chain. ${ }^{63}$ The diagram shows that Gnistan screened a sizable number of films after Biograf $A B$ Centrum's smaller, neighbourhood cinemas showing second- or third-run films had done so. In turn, a sizable number of films flowed from Gnistan to Lillan, the cinema at the bottom of the Centrum chain's hierarchy of Gothenburg cinemas. Clearly, Gnistan was a neighbourhood cinema exploiting reruns.

Of the isolates, neither Lundby, Rex or Rio advertised regularly in the local city press. It is possible that the lack of edges in the diagram is due to a lack of advertisements rather than 
screenings, in which case the cinemas may be misrepresented here. Spegeln, however, did advertise. The cinema belonged to the Cosmorama chain, was situated in the city centre and was twice the size of the other cinemas in the category of isolates (see Figure 10). Its status as isolate is explained by the kind of films it screened: amongst its repertoire were films produced in France alongside classics such as The Testament of Dr. Mabuse and Gone With the Wind, the latter a recurring weekend event.

\section{Time-plot analysis}

A time-plot analysis shows that new films from two major Hollywood production companies, MGM and Paramount, and two minors, Columbia and Republic, moved continuously from cinema to cinema after release without time intervals. This is interesting, as it differs from the exhibition patterns in Antwerp and, as we will see, Rotterdam. The analysis also reveals that films largely remained in the cinemas within a chain. ${ }^{64}$

The time-plot analysis confirms the results of the analysis of the film flows, in that films often remained within the venues of a particular chain. Furthermore, the time-plot analysis shows that this occurred without interruption, in intervals extending from one to six weeks depending on the film and the production company. The films from the two major studios we sampled were screened for a

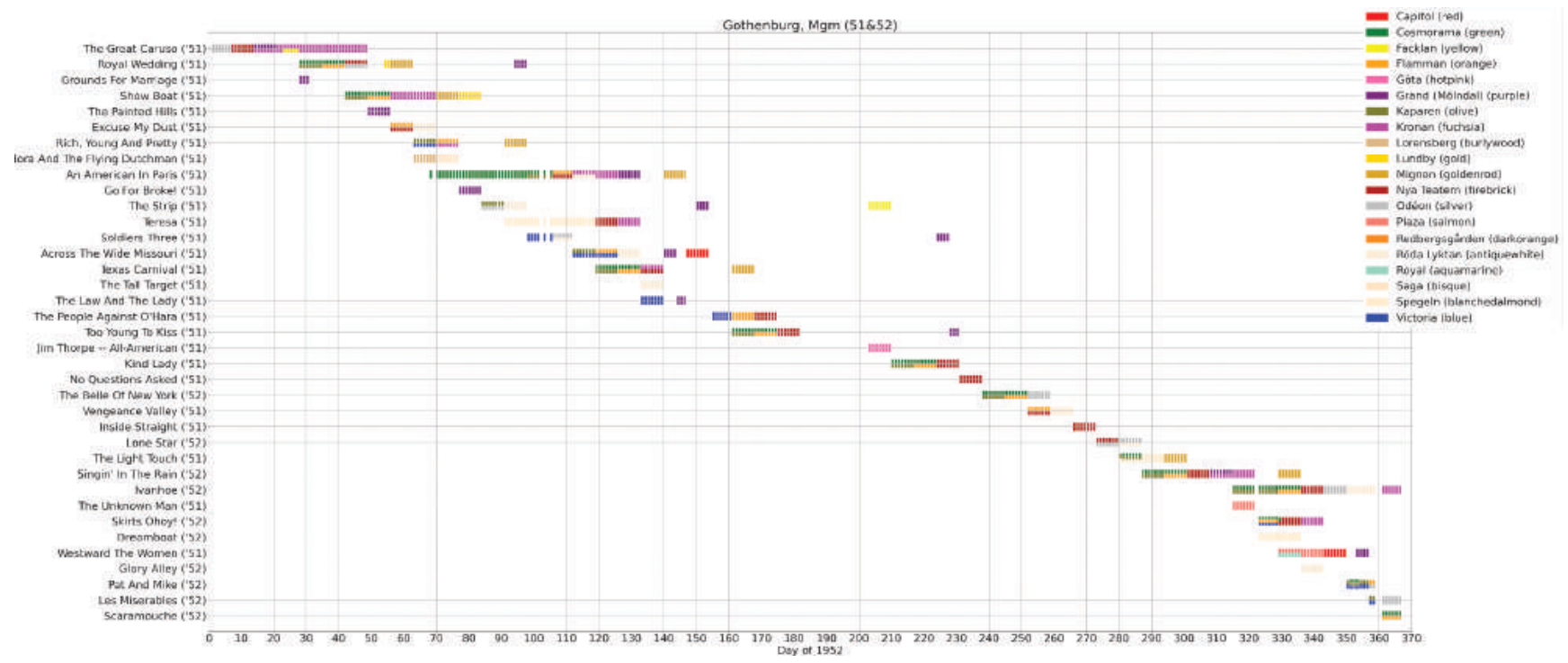

Figure 11. Time plot visualisation for all films produced by MGM in 1951 and 1952 that screened in Gothenburg cinemas in 1952. The X-axis represents the number of days that a film screened, starting with the first day in 1952 that a screening was documented for cinemas in Gothenburg. 


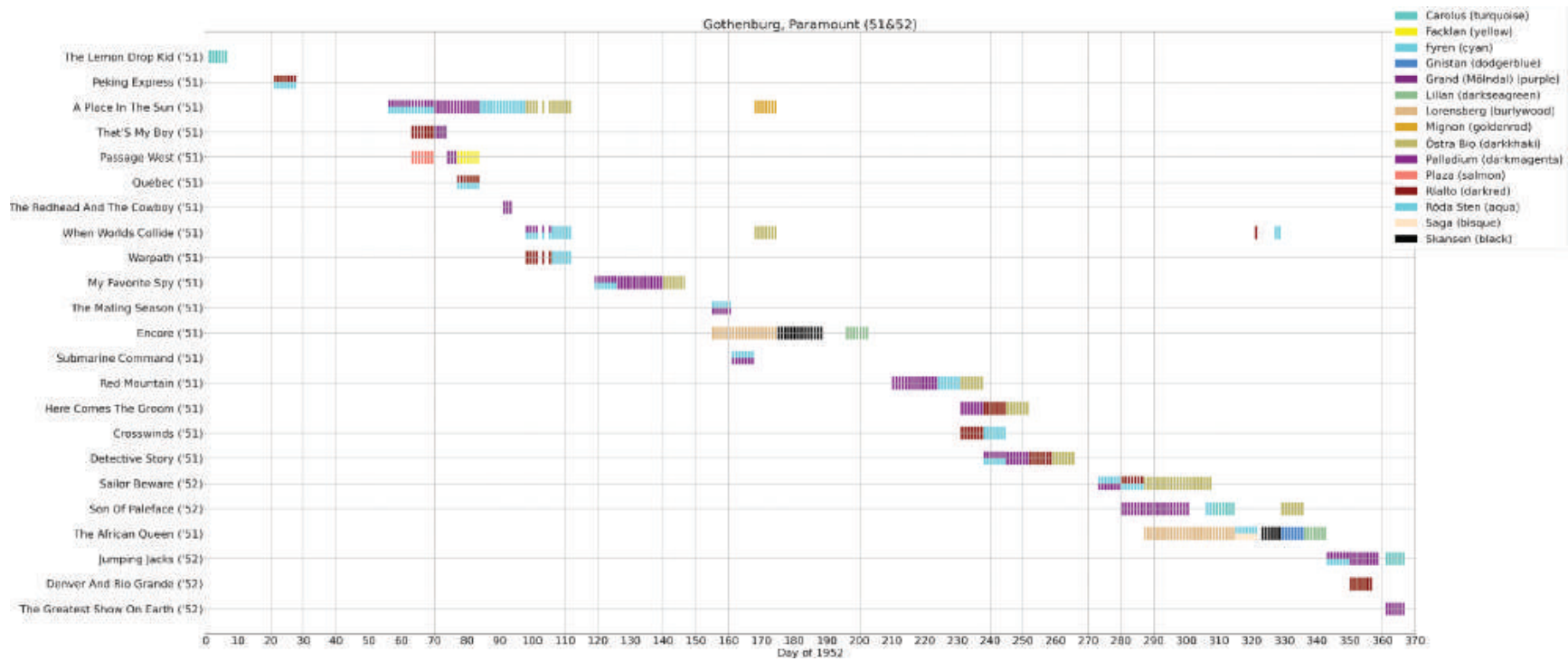

Figure 12. Films produced in 1951 and 1952 by Paramount, exhibited in Gothenburg in 1952.

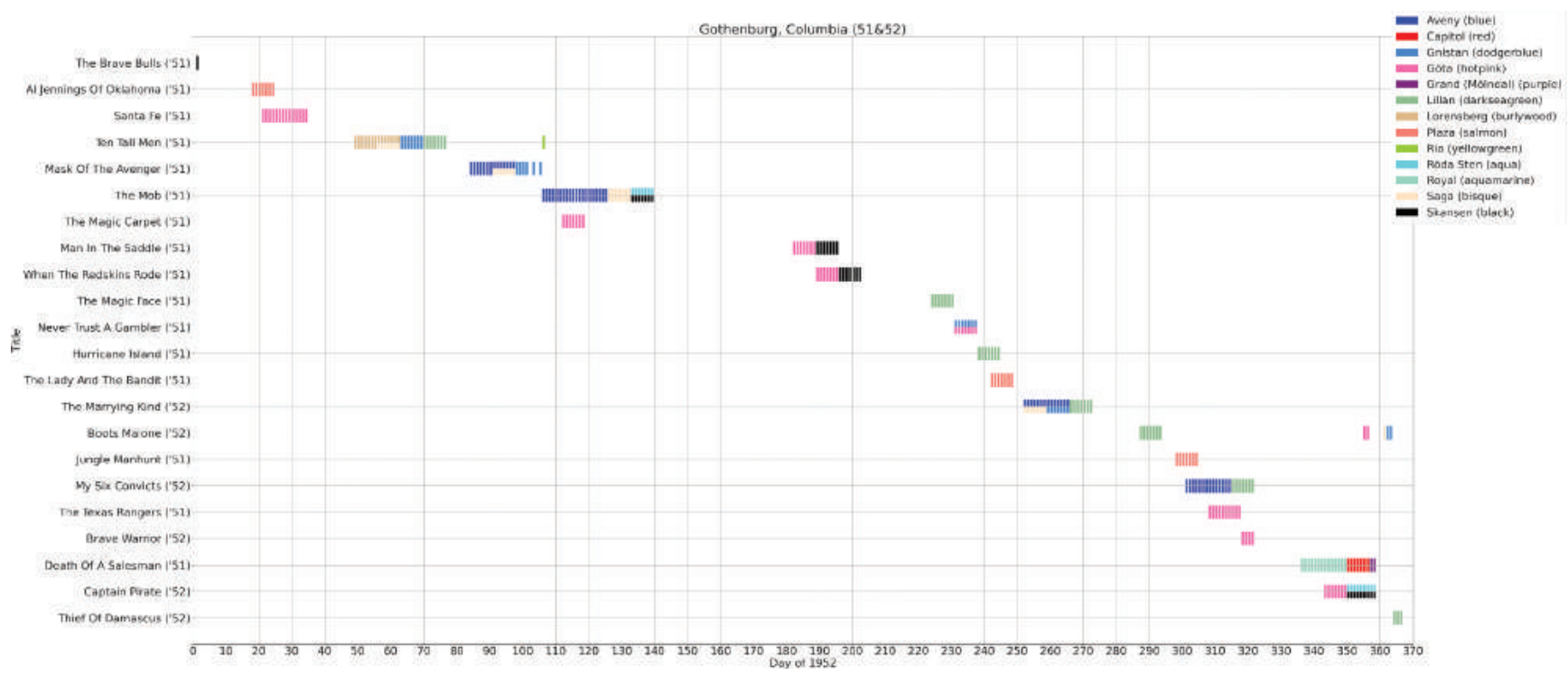

Figure 13. Films produced in 1951 and 1952 by Columbia, exhibited in Gothenburg in 1952.

longer duration than those from the two minors. A trait shared by films from all four companies, however, is that there was no clearance window as films moved over. In addition, once the new films had played out their term, they would rarely return in the same year. In a few cases, however, this did occur. When it did, the move-over cinema did not belong to the chain in which the film was originally shown and, typically, the cinema would be small or situated in an off-centre location. 


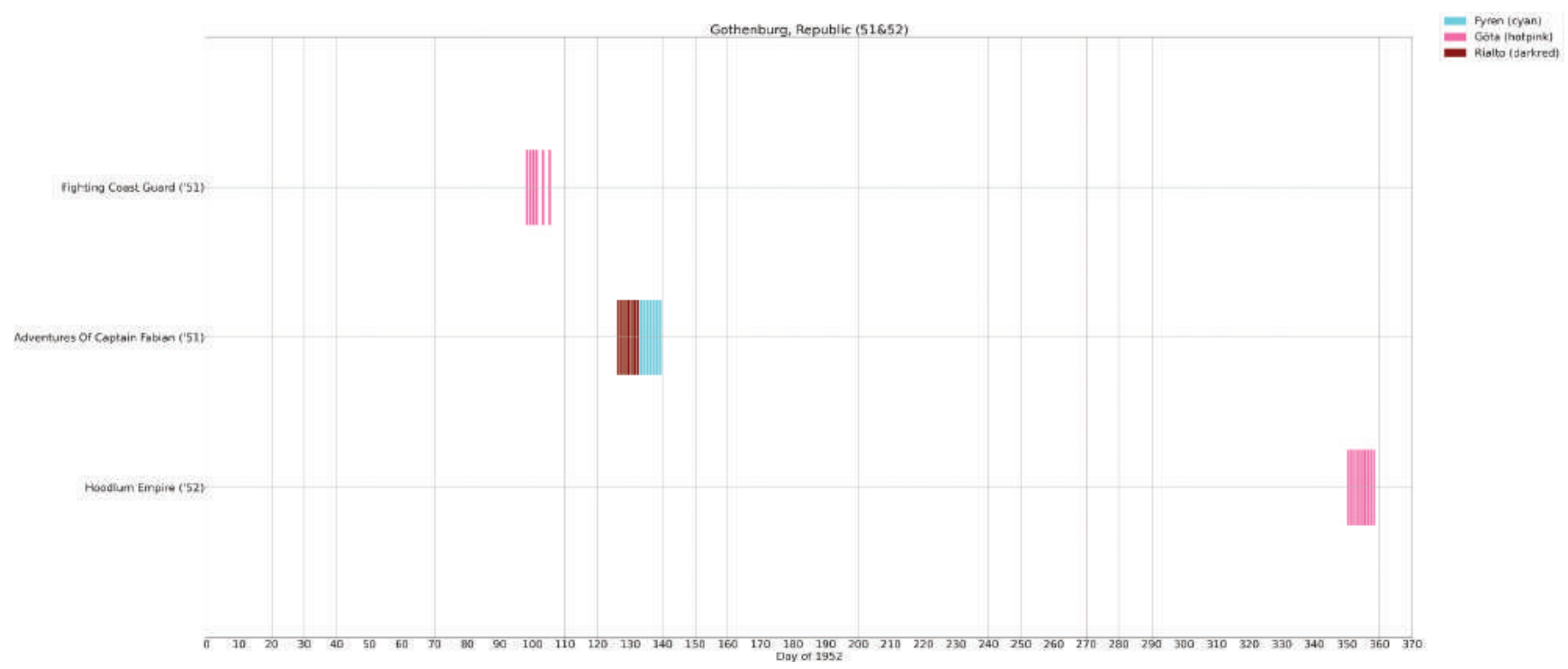

Figure 14. Films produced in 1951 and 1952 by Republic, exhibited in Gothenburg in 1952.

The MGM films playing in the $\mathrm{AB}$ Cosmorama chain show a recurring exhibition pattern (see Figure 11). As many as 23 films moved from one cinema to one or two other cinemas within the chain after a week in the first-run cinema, with no clearance window separating the runs. It was fairly common for an MGM film to play in four cinemas or more within a continuous time frame. Indeed, five films - The Great Caruso, Show Boat, An American in Paris, Singin' in the Rain and Ivanhoe - played in six or more cinemas without a break over the course of five or more weeks.

\section{Rotterdam}

The rebuilding of the Rotterdam cinema park did not really get off the ground until the mid-1950s. This inhibited the cinema market in 1952: supply could not properly adjust to demand as cinema exhibitors were unable to expand their businesses. ${ }^{65}$ The destruction of the centre cinemas shifted the gravity from the city's heart towards theatres outside the centre that had survived the 1940 flames. The Rotterdam movie landscape of the early 1950s was dominated by the Tuschinski company, even if its Jewish founders did not survive the war. ${ }^{66}$ The Tuschinski company was the only operator that had full control over more than one venue in the city in 1952, controlling the 1,000-seaters Capitol (west), Arena (centre-west), the Schiedam Passage Theatre (west) and a share of Lutusca cinema (centre). 


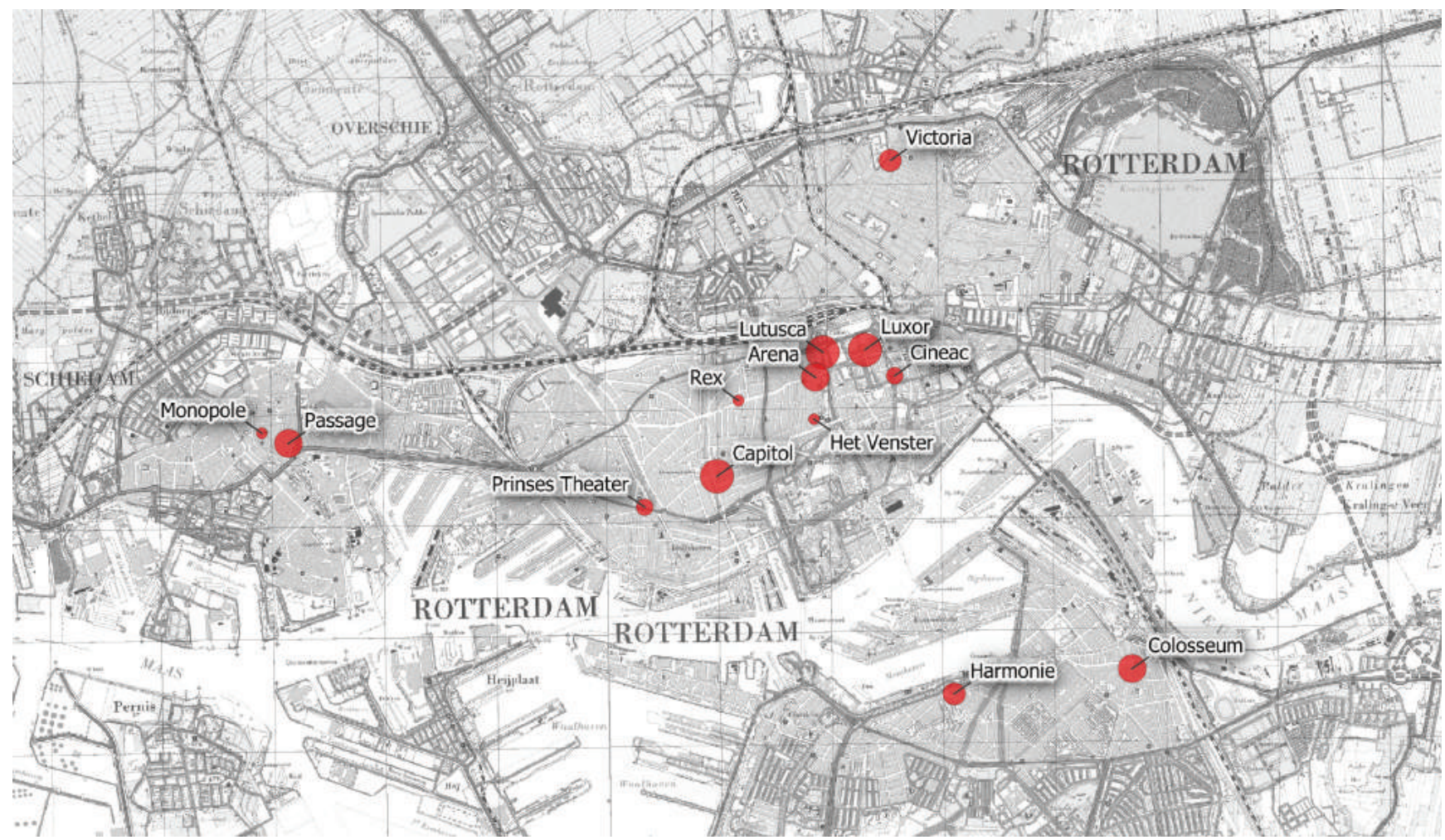

Figure 15. Map of Rotterdam, showing the location of the cinemas included in the programming analysis. The size of the dots refers to the relative size of the cinema as measured by its seating capacity. Basemap 'Gemeentewerken Rotterdam' (1963), Rotterdam City Archives.

The cinema sector in post-war Netherlands can be divided into two categories: companies that ran cinemas in several large Dutch cities and single-venue family businesses. City N.V. was the most prominent of this first category, owning theatres in The Hague and Amsterdam. In pre-war Rotterdam it had operated Lumière cinema, which was rebuilt in 1955. Before that, its main outlet was the Luxor theatre (centre), a venue seating 1,200 patrons which was confiscated by the government from UFA after the war and temporarily rented out to City. Besides Luxor, it shared the exploitation of the Lutusca emergency cinema, seating just over 1,000. Lutusca had been built in 1946, when the municipality allowed just one single building permit for a new cinema, prioritising building capacity for projects deemed more urgent such as the repair of the harbour facilities (see Figure 16). This forced cooperation between three competitors that had lost cinemas during the war, merged into the acronym Lutusca (LUmière for City's lost cinema, TUschinski, and the destroyed Scala cinema, which did not operate any other Rotterdam cinemas in 1952). One of the other larger chains was Cineac N.V. 


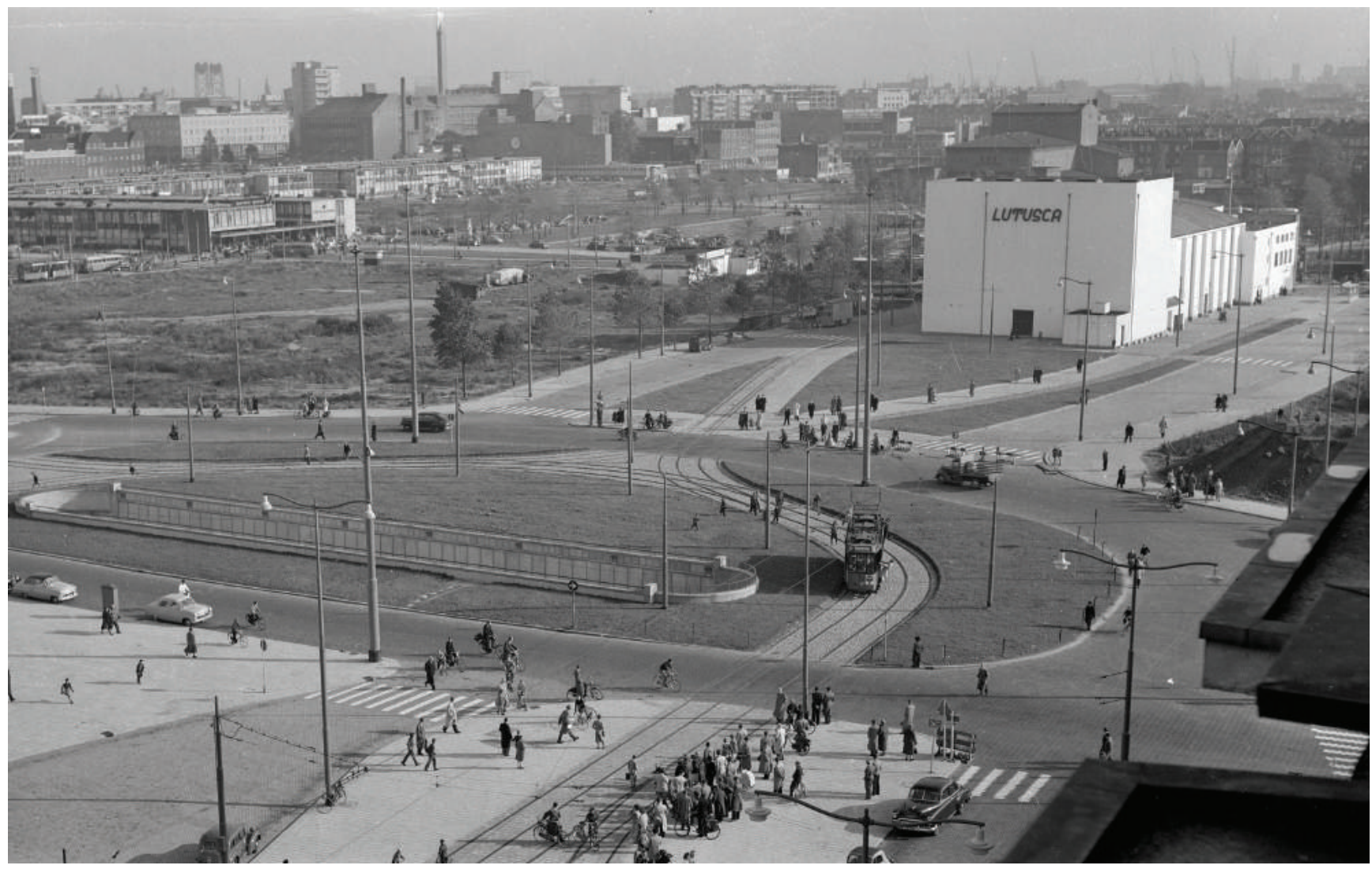

Figure 16. Aerial photo depicting Lutusca Cinema in Rotterdam (Photo by Lex de Herder, ca. 1953-1956; source: Rotterdam City Archives, https://collecties.stadsarchief.rotterdam.nl/detail.php?id=345378).

It specialised in newsreel cinemas in the country's largest cities: Amsterdam, Rotterdam and The Hague. Its Rotterdam Cineac theatre (centre) was more of a hybrid, with newsreels and cartoons during the day and feature films in the evenings; at 600 seats it was a relatively small venue. A third small chain that operated beyond Rotterdam, again focusing on the three largest cities, was Chermoek's company, which ran the Prinses Theatre in the west of Rotterdam. With a 700 seat capacity, it was also quite small.

The other category of Rotterdam cinemas were small family businesses that had been active since before the war, running mostly mid-sized or small theatres. Some were able to turn the scarcity of screens to their advantage, as the analysis below seems to suggest. The South Bank of the Nieuwe Maas was a large working class residential area that housed two independently owned cinemas in 1952: Harmonie (710 seats) and Colosseum, which, with 1,028 seats, was quite large for a neighbourhood 
TMG $23(1 / 2) 2020$

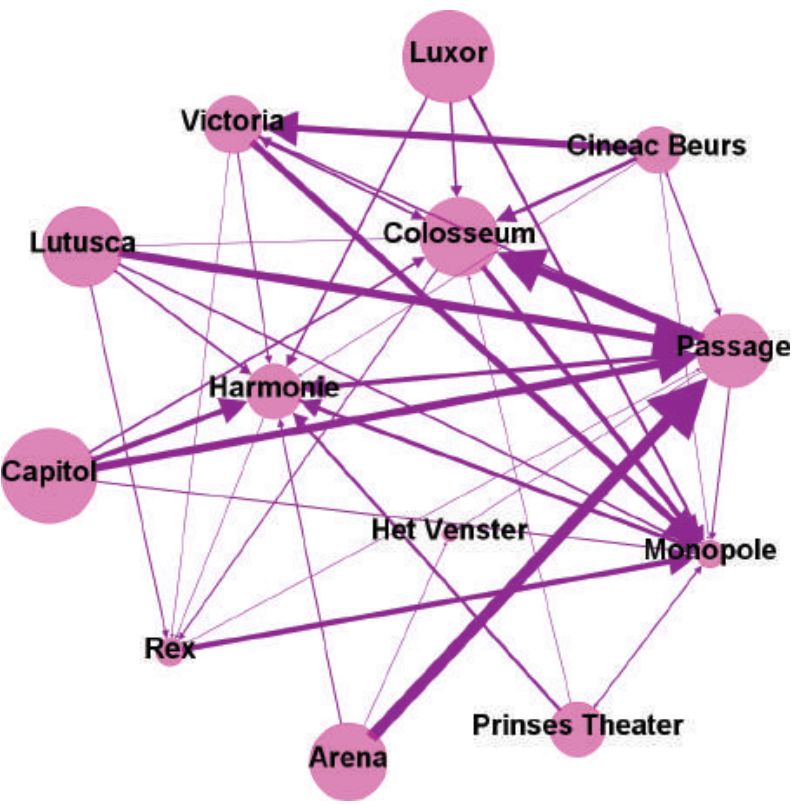

Figure 17. Flow of films for the Rotterdam dataset, edge weight 1.

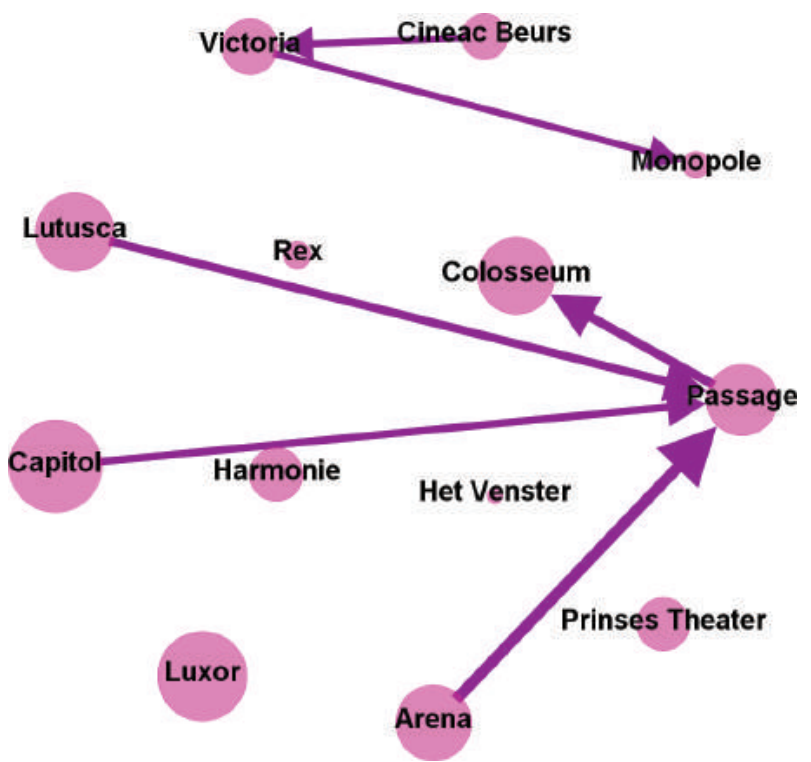

Figure 18. Flow of films for the Rotterdam dataset, edge weight 8. 
cinema. ${ }^{67}$ In the northern part of the city there was the family-run Victoria (743 seats). Two small cinemas located on the western side, Rex (348 seats) and Monopole in Schiedam (340), had a reputation for showing 'boys' cinema', screening westerns and crime films. The smallest venue in the city was the art-house cinema Het Venster (184).

Figure 18 depicts the flow of films in Rotterdam cinemas in 1952 with a threshold of at least eight edges (shared films) or more. In addition to the set of isolates, two clusters emerge from the visualisation: Cineac-Victoria-Monopole and a cluster that has Passage as its central node. This latter cluster highlights the function of Passage as a second-run theatre in the Tuschinski chain, systematically screening titles after Tuschinksi’s first run venues Arena, Capitol and Lutusca. Similar to that of Kaparen in Gothenburg, Passage can be interpreted as a first-run theatre for local Schiedam audiences, for whom the tram or bicycle ride to the Rotterdam city centre could be a barrier. In relation to the unaffiliated Colosseum neighbourhood theatre in Rotterdam-Zuid, Passage can be characterised as a first screening venue; it screened the films before Colosseum. It is interesting to note that there was a connection between Colosseum and Passage but no direct link between Colosseum and the Tuschinski premiere theatres. Tuschinski did not own any venues in the south of Rotterdam (it had plans to open a cinema there, but they never materialised). ${ }^{68}$

The other cluster shows how the management of the Victoria appeared to seize the opportunity in the post-war landscape to position the cinema as a second-run (and sometimes even first-run) venue of sorts, even though it was a small, family-owned cinema that one would not expect to have a high position in the distribution hierarchy. This analysis is supported by the fact that Victoria regularly shared first runs with centre cinema Cineac; this is not visible in the network graph but evident in Table 4. It seems that Victoria was able to make good use of the screen shortage experienced in the city until the mid-1950s. ${ }^{69}$ In the same cluster, Cineac functioned as a first run theatre. It had a small seating capacity for a premiere theatre (600), which could perhaps be one of the reasons that the management apparently collaborated on a regular basis with two neighbourhood cinemas to simultaneously release films: Victoria (in the north) and Colosseum (in the south; see table 4). Allowing a wider exposure for Rotterdam premieres via distribution over two or three venues that were geographically dispersed might have afforded a better bargaining position with distributors for the exhibitors involved. Although we can only speculate about the exact reasoning behind this apparent business collaboration, it is noteworthy that this kind of film flow analysis enables us to point out links and combinations that might otherwise remain unobserved. 
Finally, there are the isolates. When we compare Victoria to another small neighbourhood cinema, Harmonie, in the southern suburbs, we see a programming strategy different from Victoria's. Harmonie screened films with earlier runs in just about any cinema in Rotterdam. Though Harmonie had many connections to the other Rotterdam cinemas, these connections are divided fairly evenly across the cinema landscape (see Figure 17). That is why Harmonie appears isolated in the visualisation in Figure 18: no single cinema stood out with a strong relation to Harmonie sharing 8 or more films. The same applies more or less for Rex, even if the degree of interconnectedness to the network of Rex is lower. Het Venster self-identified as an art cinema. With its specialised programming, it is not surprising that titles screened there rarely appeared in other cinemas in the city.

More curious is the relative isolation of the two remaining cinemas that were not typical small family businesses. The Prinses Theatre seems relatively isolated, but this theatre was, unlike Harmonie and Rex, a first screening venue (see Figure 17). This might indicate that Prinses, as part of a (small) chain that was also active beyond Rotterdam, had its own distinct, perhaps even exclusive, distribution contacts. ${ }^{70}$ Luxor has a similar position of relative isolation and, like Prinses, can be regarded as a first screening venue. Both cinemas showed the films before they were screened in one of three neighbourhood theatres Colosseum, Harmonie and Monopole.

To summarise, the analysis of film flow reveals a hierarchy of first-run cinemas: Lutusca, Arena, Capitol, Cineac, Luxor and Prinses, of which only the first four seem to be integrated into clusters of more-or-less fixed routes of consecutive re-screenings of films. Although there is no clear-cut distinction between second and third run houses, we can nonetheless distinguish between cinemas that showed films in consecutive runs: some are more equal than others. Passage and Victoria are prominent second-run cinemas that passed on films for third runs to, respectively, Colosseum and Monopole. However, Colosseum is not a typical third-run cinema, as it also screened films that were shown in Prinses, Luxor and Cineac first. More clearly at the bottom of the pecking order are Rex, Monopole and Harmonie. With regards to seating capacity and how this plays into the system, mostly the movement follows the logic of movement from large to smaller, except for the uncharacteristically large Colosseum and small Cineac.

\section{Time plots}

The number of films from the four selected Hollywood studios that are visualised in the time plots is quite low for Rotterdam, yet the time plots do offer evidence of both the length of clearance windows and the extent to which exhibitors shared the offerings from the same studios. 


\begin{tabular}{|c|c|c|c|}
\hline Frequency & Cinema & Cinema & Cinema \\
\hline 7 & Colosseum & Victoria & \\
\hline 6 & Cineac Beurs & Victoria & \\
\hline 4 & Luxor & Prinses Theater & \\
\hline 3 & Cineac Beurs & Colosseum & Victoria \\
\hline 3 & Cineac Beurs & Colosseum & \\
\hline 1 & Arena & Capitol & \\
\hline
\end{tabular}

Table 4. Simultaneous first runs in Rotterdam 1952.

Similar to Antwerp and in contrast to Gothenburg, clearance windows were standard practice in Rotterdam. The number of films shown here is too small to make inferences about the average length for the clearance window, but the time plot analysis does suggest that the clearance window was smaller when a film moved between Rotterdam and Schiedam (Passage or Monopole). This might (possibly) be explained by the municipal boundaries separating Schiedam from Rotterdam, though they were integrated in the larger city agglomeration, which may have imposed regulations for films crossing over from one municipality to another.

Films produced by Paramount were predominantly screened in Tuschinski theatres; four out of eight Paramount films were screened (and probably premiered) in Arena, with second runs in Passage, both managed by Tuschinski. A fifth screening was in Lutusca in which Tuschinski owned a share. However, judging from this small sample, Tuschinski did not have an exclusive arrangement with Paramount, because three out of eight films had their first screening in competing cinemas (Victoria and Luxor). ${ }^{71}$ Films produced by Paramount were screened predominantly in the CineacVictoria cluster that we identified in the network graphs. Eight out of fourteen screenings took place at Cineac, often simultaneous with Victoria and sometimes also in combination with Colosseum as a third screen. Three first screenings took place in Luxor and three in Lutusca. Remarkably, only four films returned for a consecutive screening within the calendar year. 
TMG $23(1 / 2) 2020$

Clara Pafort-Overduin, Kathleen Lotze, Åsa Fernudd and Thunnis van Oort

Columbia films were hardly present in the top tier cinemas, with only six out of eleven titles screened at premiere theatres (three in Prinses, two in Lutusca, and one on Capitol). Only one film title from Republic studios was screened in Rotterdam.

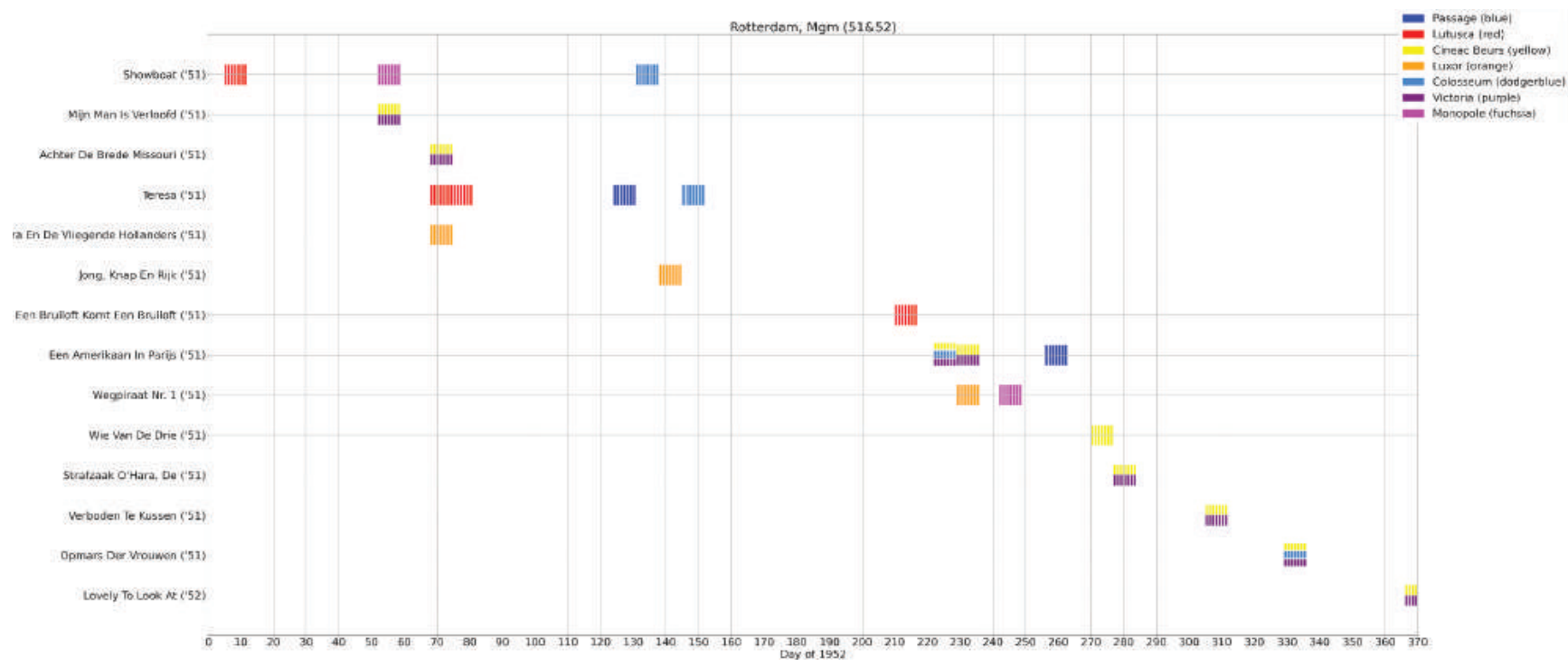

Figure 19. Time plot visualisation for all films produced by MGM in 1951 and 1952 that screened in Rotterdam cinemas in 1952. The $X$-axis represents the number of days that a film screened, starting with the first day in 1952 that a screening was documented for cinemas in Rotterdam.

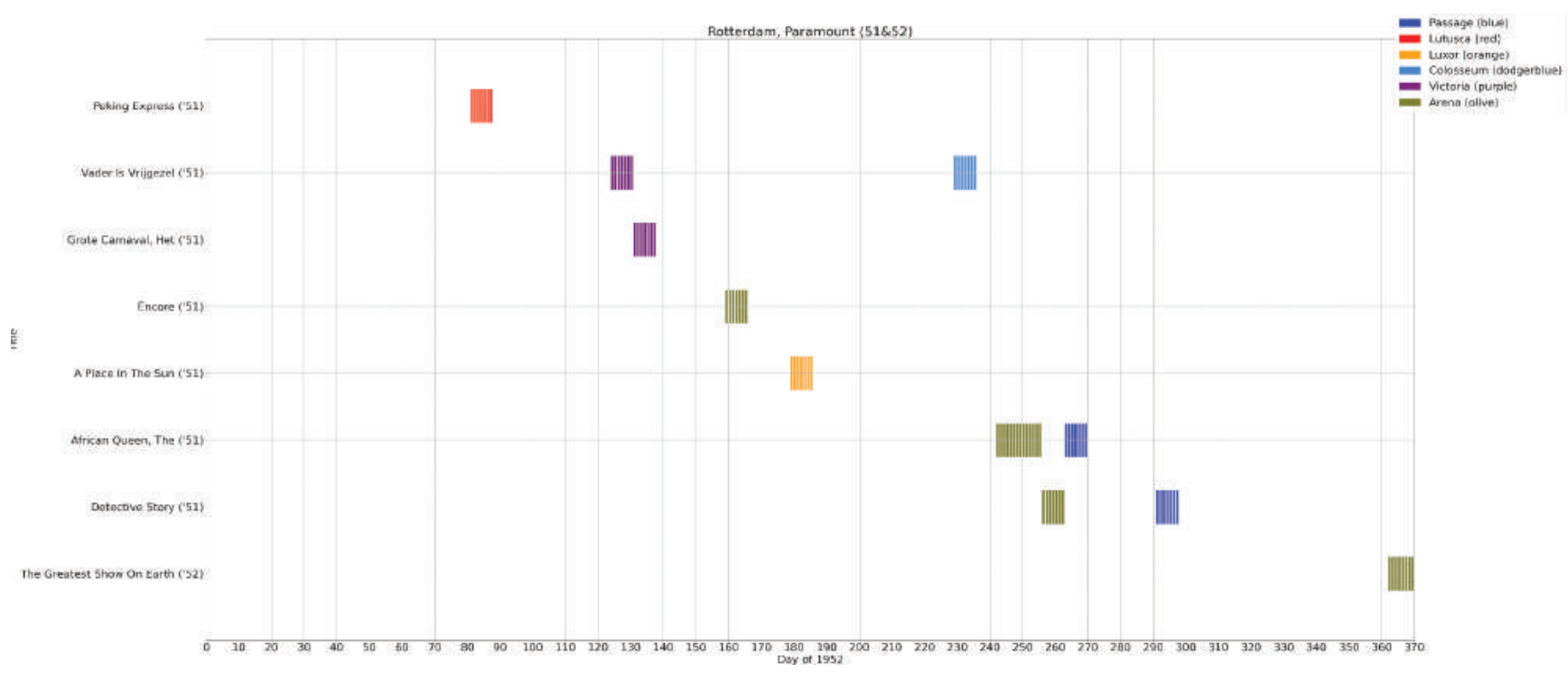

Figure 20. Films produced in 1951 and 1952 by Paramount exhibited in Rotterdam in 1952. 


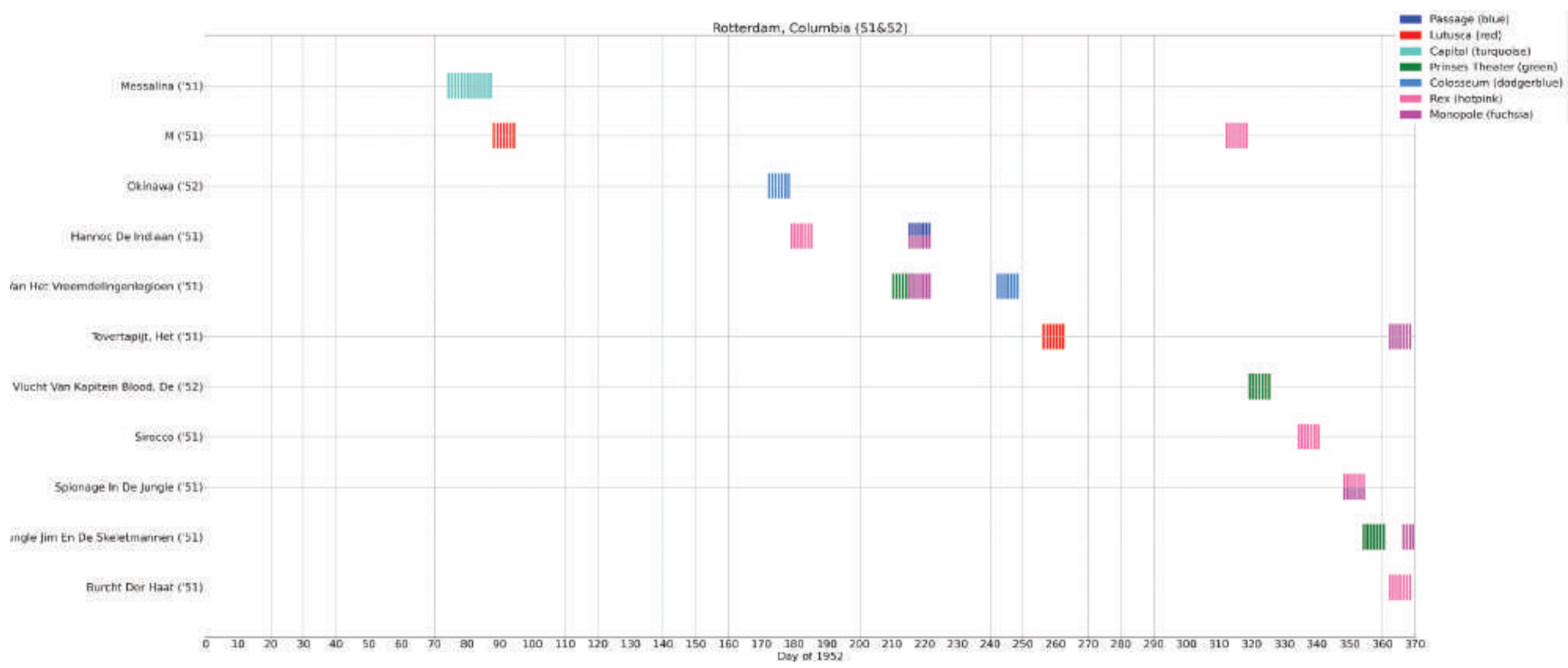

Figure 21. Films produced in 1951 and 1952 by Columbia exhibited in Rotterdam in 1952.

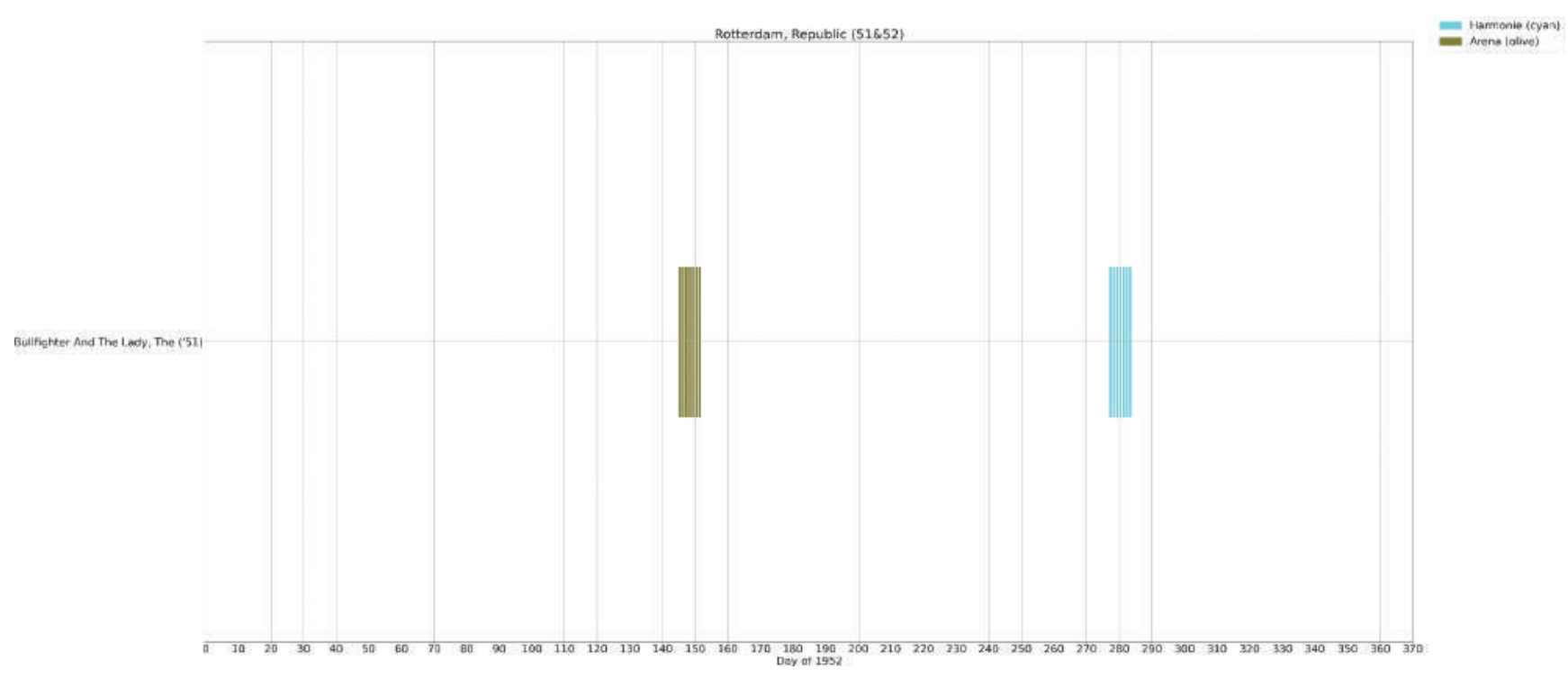

Figure 22. Films produced in 1951 and 1952 by Republic exhibited in Rotterdam in 1952.

\section{Conclusions}

We embarked on this collaborative project because we wanted to establish whether the mapping of cinemas, together with visualisations of the movements of films between cinemas, would give us new perspectives on and insights into the way film distribution and exhibition functioned in 
European cities, an under-researched topic. First, we examined the relationships between cinemas, represented as a network that shared (or did not share) films in the sample year 1952. Already, the general statistics that underpin the network graphs reveal some striking differences between the cinema markets under consideration: the exceptionally small Rotterdam market, where only one tenth of the films returned to another cinema in the same year, contrasts with Gothenburg, where over a third of all titles were available for a consecutive screening. More generally, these differences suggest that European moviegoers in larger, second-tier cities in 1952 experienced quite different practices brought about by different structural conditions. We are conscious, however, that there are limitations to the use of the network visualisations as historical evidence. The lack of information on prices, for example, is a serious handicap, yet the visualisations do suggest that some of the mechanisms of the classical run-zone-clearance-system are also recognisable in the three cities, albeit not completely and not in a uniform manner.

The visual display of the routes that films travelled from cinema to cinema provides insights into the relationships between cinemas in each respective city and their internal hierarchy in terms of first, second and subsequent runs of films. The network visualisations also suggest connections or collaborations between cinemas and exhibitors. When concentrating on the stronger connections of cinemas which shared at least eight films in their programming of 1952, clusters become apparent. Differences in the nature of those clusters - e.g. a single dominant cluster in Antwerp accompanied by many isolates, or a set of four clusters in Gothenburg - are illustrative of differences in the film markets of the three cities and differences in exhibition-distribution models. In part, this diversity may have emanated from differences in terms of number of cinemas, their seating capacity and the degree of market concentration.

The visualisation of networks offers an advantage over tables of programming dates, because it is possible to detect significant relationships at a glance. Though the graphs cannot serve as direct evidence of business collaborations, surprising associations (or lack thereof) produced by the visualisations can produce new points of departure for further investigations into the relations between exhibitors and distributors, using other methods. We believe that visualisations such as these network graphs can be a helpful quantitative tool to better enable a comparison of different urban cinema ecosystems. The density and coherence of the networks, the amount and thickness of edges, their direction, and the degree of clustering can assist in the discovery of new methods for identifying the differences and similarities in the varied European landscapes of cinema distribution and consumption. 
In a second set of visualisations, we focused on recent releases of a small sample of Hollywood producers and followed the life cycle of individual films through the cinema landscape, concentrating on the time of and intervals between screenings. This shows a distinct variation in the use of clearance windows in the selected European cities. The size of the sample is too small to make general statements, but it is clear that Gothenburg showed a distribution pattern different from the other two cities. In Gothenburg, consecutive screenings of films was the common rule as films moved between cinemas. In the other two cities, intervals between subsequent runs prevailed. Another remarkable characteristic, and related to this, is the long life-cycles of the films in Gothenburg. Here the relatively small size of the cinemas might have been part of the explanation: when there are fewer tickets to be sold for a screening, more screenings are required before a film becomes profitable. In other words, the low average and median seating capacity possibly created a structure that encouraged long life-cycles and more films to move.

The time plot series also demonstrate a lack of uniformity among the three European cities regarding the degree to which films produced by selected major Hollywood studios were exclusively screened in certain cinemas or chains. Even if in many cases an association was apparent between films by a certain producer and an exhibitor or chain, this was not always the case, especially in Antwerp. Here, with the exception of MGM, the connections between the other three producers and individual exhibitors were less distinct than in Gothenburg and Rotterdam. This suggests the variability of film distribution practices in Europe in this period. We therefore believe that a more systematic tracing of distributors and/or producers that goes beyond a small sample is a promising avenue for future research, not just in Europe.

The analyses for Antwerp and Rotterdam reveal some interesting similarities (apart from obvious differences such as the size of the market). Although the scale of the market was smaller in Rotterdam, the exhibition sector in both cities was organised in a comparable way, with one dominant large chain (Heylen in Antwerp, Tuschinski in Rotterdam) in addition to multiple smaller chains and exhibitors operating one single venue. Just as in Gothenburg, the exchange of films took place most systematically within the larger chains. Smaller chains and stand-alone exhibitors shared films, but the lack of clear patterns here suggests that these exchanges depended more on the particular films (producers/distributors).

Furthermore - as clearly demonstrated in the case of Rotterdam and to some extent also in Gothenburg and Antwerp - the analysis showed that location also determined how films moved 
through the city. The visualisations combined with the maps reveal that generally, films moved from larger cinemas in the city centre to cinemas with smaller seating capacities located in areas outside of the centre - a strategy characteristic of the run-zone-clearance model practiced by the Hollywood majors during the era of the studio system. The logic behind this strategy was for the distributor to maximise revenues - initially renting to larger cinemas (charging higher prices) until that particular audience was exhausted, and then subsequently renting to lower order cinemas until the film ran out of legs. Nevertheless, as our analysis shows, film premieres were not exclusive to city centre cinemas: in Rotterdam for example, a peripheral neighbourhood cinema such as Victoria was able to screen first-run films, even if this was an exception most likely induced by the disruption of the cinema landscape caused by the war. Furthermore, in Gothenburg, new releases in the Cosmorama chain offered parallel screenings in a city-centre cinema and then in another cinema situated in another part of the city. Cinemas that were located at a relative distance from each other could share films, as they were not directly in competition with one another.

The collaborative process and the findings yielded by it have reinforced our view that a quantitative approach can only work in the presence of contextual knowledge. This is evident in a comparative study in a collaborative setting, where each individual researcher has limited knowledge and understanding of the contexts of the other cases. Furthermore, the idea of striving for completeness easily arises with larger datasets. It can be difficult to effectively analyse the overall picture when working with big data. This makes paying attention to the accountability and provenance of the data all the more vital. Working in a collaborative team can accentuate these difficulties.

A consequence of this is that considerable attention must be paid to deciding which data will be collected for comparison, describing the data that is available, and thinking about the design of the format of the dataset. The data compiled from separate sources or collections have to be adjusted to the task at hand in advance of the analysis. This is the only way to avoid comparing apples with pears. Nonetheless, data-driven approaches such as the one adopted in this article open up new methods for exploring existing datasets, evoking new questions and providing a new footing for comparative analyses that also facilitate qualitative approaches.

With larger datasets, it is possible to see the value of local practices and make a statement about their specificity. Extending the scope of historical studies (either temporally or geographically) allows us to place these in-depth and precise case studies in a certain perspective. That is what our comparison has also yielded. It exposes differences in the local market dynamics caused by the size 
of the market, the size of the cinemas and ownership of the cinemas. It is extremely clear from our findings that there was no set manner in which the films flowed in one city from cinema to cinema, and that there is no one readily available explanation for the patterns shown in the visualisations. These findings have convinced us that distribution is integral to understanding and comparing cinema markets. Programming information - which film was shown in what cinema at what point in time - is an excellent starting point for this. However, when enhanced with information about distributors, a more comprehensive comparative analysis of how different cinema markets functioned is possible.

\section{Acknowledgements}

The authors would like to thank Ivan Kisjes for his help with harmonising the data and creating the time plot charts; Leon van Wissen for his assistance in producing statistics on the data; Jaap Boter for his help on a first version of the maps; and John Sedgwick for his insightful comments on an earlier version.

\section{Notes}

1 Deb Verhoeven, "Show Me the History! Big Data Goes to the Movies," in The Arclight Guidebook to Media History and the Digital Humanities, ed. Charles R. Acland and Eric Hoyt (n.p.: Reframe Books, 2016), 169-183. Deb Verhoeven is a pioneer in developing online research resources regarding big cultural data, for example the Cinema and Audiences Research Project (CAARP) database.

2 See, for example, Joseph Garncarz, Wechselnde Vorlieben: Über die Filmpräferenzen der Europäer 1896-1939 (Frankfurt/Basel: Stroemfeld, 2015); Thunnis van Oort, "Industrial Organization of Film Exhibitors in the Low Countries: Comparing the Netherlands and Belgium, 1945-1960," Historical Journal of Film, Radio and Television 37, no. 3 (2016): 475-498, https://doi.org/10.1080/01439685.2016.1157294; Clara PafortOverduin, John Sedgwick and Lies Van de Vijver, “Identifying Cinema Cultures and Audience Preferences: A Comparative Analysis of Audience Choice and Popularity in Three Medium-Sized Northern European Cities in the Mid-1930s," TMG Journal for Media History 21, no.1 (2018): 102-118, http://doi.org/10.18146/22137653.2018.340; Daniel Biltereyst, Thunnis van Oort and Philippe Meers, “Comparing Historical Cinema 
Cultures: Reflections on New Cinema History and Comparison with a Cross-National Case Study on Antwerp and Rotterdam," in The Routledge Companion to New Cinema History, ed. Daniel Biltereyst, Richard Maltby and Philippe Meers (London: Routledge, 2019), 96-111.

Cinema City Cultures is a network of collaborative research inspired by the project, "The "Enlightened" City: Film exhibition and film consumption in Flanders (1895-2004)'. The network is an initiative of Philippe Meers and Daniel Biltereyst. For an overview of the projects involved in Belgium, Brazil, Colombia, Mexico, Spain, the Netherlands and the US, see www.cinemacitycultures.com/ projects.

4 The European Cinema Audiences Project (2018-2021) is financed by the British Arts and Humanities Research Council and compares film cultures in seven mid-sized European cities in the 1950s. See https://www.europeancinemaaudiences.org/.

5 Methodological Workshop. Researching and Comparing Historical Cinema Cultures: Film Popularity and Mapping, in Frankfurt am Main, 16-18 January 2020. Organized by Karina Pryt within the framework of the DFG funded project: Cinema Culture in Warsaw 1895/6-1939; Symposium. A Transnational Perspective: Movie Theatres in Wartime. Comparative Research on Film Distribution and Exhibition During World War II, virtual meeting on June 5, 2020 and planned meeting in Amsterdam, 19-21 November, 2020. Hosted by the Institute for War, Holocaust and Genocide Studies and the University of Amsterdam, organised by CREATE (University of Amsterdam) and DICIS (Scientific Research Network on Digital Cinema Studies).

6 'Gephi is an open-source software for network visualization and analysis. It helps data analysts to intuitively reveal patterns and trends, highlight outliers and tells stories with their data. It uses a 3D render engine to display large graphs in real-time and to speed up the exploration.' See: https://gephi.org/about/.

7 R.V. Cardoso and E.J. Meijers, “Contrasts Between First-Tier and Second-Tier Cities in Europe: A Functional Perspective," European Planning Studies 24, no. 5 (2016): 996-1015, https://doi.org/10.1080/09654313.2015. 1120708.

8 M. Gyory and G. Glas, Statistics of the Film Industry in Europe (Brussels: The European Centre for Research and Information on Film and Television, 1992).

9 Göran Therborn, European Modernity and Beyond: the Trajectory of European Societies, 1945-2000 (London: Sage, 1995), 26, 133-135.

10 Lennart Schön, An Economic History of Modern Sweden (London: Routledge, 2012), 210.

11 Robert Vandeputte Economische geschiedenis van België, 1944-1984 (Tielt/Weesp: Lannoo, 1985), 30-31. 
12 Paul T. van de Laar, Stad van formaat: geschiedenis van Rotterdam in de negentiende en twintigste eeuw (Zwolle: Waanders, 2000); C. J. M. Schuyt, 1950: Welvaart in zwart-wit, Nederlandse cultuur in Europese context 4 (Den Haag: Sdu Uitgevers, 2000).

13 Thunnis van Oort, "Resurrection in Slow Motion: The Delayed Restoration of the Cinema Exhibition Industry in Post-War Rotterdam (1940-65)," European Review of History, no. 6 (2018), 999-1017, https://doi.org/10.1080 /13507486.2017.1374928.

14 Bertil Andersson, Martin Fritz and Kent Olsson, Göteborgs historia: näringsliv och samhällsutveckling. 3 Från industristad till tjänstestad 1920-1995 (Stockholm: Nerenius \& Santérus, 1996), 40-42, 415-419.

15 Douglas Gomery, The Hollywood Studio System. A History (London: BFI, 2005), 18-25.

16 Gomery, The Hollywood Studio System, 18-25.

17 F. Andrew Hanssen, “The Block Booking of Films Re-examined” in An Economic History of Film ed. John Sedgwick and Michael Pokorny (London/New York: Routledge, 2005), 137-139.

18 Hanssen, “The Block Booking of Films Re-examined," 132-134, 140.

19 Arthur De Vany. Hollywood Economics. How Extreme Uncertainty Shapes the Film Industry (London/New York: Routledge, 2004), 160.

20 See for example: Clara Pafort-Overduin, “'Voorlopig zijn de rollen omgekeerd.' Hoe de Nederlandse Bioscoopbond de Motion Picture Export Association aftroefde," in 100 jaar branchevereniging van bioscopen in Nederland - Van Nederlandse Bioscoopbond naar Nederlandse Vereniging van Bioscopen en Filmtheaters ed. Frank Westra, Gulian Nolthenius, Jorien Scholtens, Evelien Sinke ajd Ron Sterk (Amsterdam: NVBF, 2018), 100-101.

21 Jack Alicoate, ed., The 1951 Film Daily Year Book of Motion Pictures (New York: Wid's Films and Film Folks Inc, 1951), 551. Alicoate, The 1951 Film Daily Year Book. Kathleen Lotze and Philippe Meers, “'They Don’t Need Me In Heaven...There Are No Cinemas There, Ye Know’: Cinema Culture in Antwerp (Belgium) and the Empire of Georges Heylen, 1945-75," in Watching Films: New Perspectives on Movie-Going, Exhibition and Reception, ed. Karina Aveyard and Albert Moran (Bristol and Chicago: intellect, 2013), 231-233; Daniel Biltereyst, Philippe Meers and Lies Van de Vijver, “Social Class, Experiences of Distinction and Cinema in Postwar Ghent," in Explorations in New Cinema History: Approaches and Case Studies, ed. Richard Maltby, Daniël Biltereyst and Philippe Meers (Malden/Oxford: Wiley-Blackwell, 2011), 108.

24 SOU 1951:1. Statligt stöd åt svensk filmproduktion. [State Public Report 1951:1. State Support of Swedish Film Production] (Stockholm: Nordiska bokhandeln, 1951), 55-59, http://urn.kb.se/ resolve?urn=urn:nbn:se:kb:sou-1448258. 
25 Karel Dibbets, “Bioscoopketens in Nederland. Ekonomiese koncentratie en geografiese spreiding van een bedrijfstak, 1928-1977,” (MA thesis, University of Amsterdam, 1980), 54-60.

Harry van Vliet, Karel Dibbets and Henk Gras, “Culture in Context. Contextualization of Cultural Events,” in Digital Tools in Media Studies: Analysis and Review, ed. M. Ross, M. Grauer and B. Freisleben (Berlin: Transcript, 2009), 28.

27 Julia Noordegraaf, Kathleen Lotze and Jaap Boter, "Writing Cinema Histories with Digital Databases: The Case of Cinema Context,” TMG Journal for Media History 21, no. 2 (2018), 106-126.

28 See, for example, the Mapping Movies project, pioneered and curated by Jeff Klenotic, an Environmental Response Management Application (ERMA) created by the University of New Hampshire and designed to invite mapping as a heuristic process of research and learning, see http://www.mappingmovies.com/; DocSouth: Going to the Show, (The University Library, The University of North Carolina at Chapel Hill, 2008), see http://gtts.oasis.unc.edu/; Colin Arrowsmith, Deb Verhoeven and Alwyn Davidson, "Exhibiting the Exhibitors: Spatial Visualization for Heterogeneous Cinema Venue Data,” The Cartographic Journal 51, no. 4 (2014), 301-312, https://doi.org/10.1179/1743277414Y.0000000096. For a more comprehensive overview of recent projects involving mapping cinemas and films, see Digital HoMER, http:// homernetwork.org/dhp-projects/homer-projects-2/.

29 Jeff Klenotic, "Putting Cinema History on the Map: Using GIS to explore the spatiality of cinema," in Explorations in New Cinema History Research, ed. Richard Maltby, Daniel Biltereyst and Philippe Meers (Malden, MA: Wiley-Blackwell, 2011), 58-84; Laura Horak, “Using Digital Maps to Investigate Cinema History," in The Arclight Guidebook to Media History and the Digital Humanities, ed. Charles R. Acland and Eric Hoyt (University of Sussex, UK: Reframe Books, 2016), 65-102.

30 Exceptions are the pioneering work of film scholar Karel Dibbets and the more recent Australian Kinomatics project: Dibbets, "Bioscoopketens in Nederland.”; Deb Verhoeven, Bronwyn Coate, Colin Arrowsmith and Stuart Palmer, “Using Big Cultural Data to Understand Diversity and Reciprocity in the Global Flow of Contemporary Cinema," in Proceedings of the international symposium on the measurement of digital cultural products (Montreal: UNESCO Institute for Statistics, 2016), 141-151.

31 Dibbets, "Bioscoopketens in Nederland," 10.

32 The NBB was a cartel established in 1921 to represent the interest of exhibitors by regulating the film supply, in order to oppose the restrictive measurements by Dutch governments (high taxes, censorship, negative moral discourse). 

avoid confusion with existing communication models. Instead, we looked for a terminology that does not mark the cinema as an agent but as a place where a film arrives at a certain moment in time - first or subsequent runs. We aim to express the moment in time as a characteristic of the cinema's position in the network without using the words 'first run' and 'second run', because this refers to the status of the cinema in distribution practices and, in our case, the first screening venue does not automatically equate to a first run theatre with premiere films only.

37 For more explanation on Fruchterman Reingold see: https://github.com/gephi/gephi/wiki/FruchtermanReingold, accessed 4 February 2020.

38 The decision to put the threshold at eight edges was a pragmatic one and was made after testing at which edge weight the visualisation showed an obvious consecutive change for all four cities without losing important information or nuances in the networks.

39 See European Cinema Audiences. Entangled Histories and Shared Memories, www. europeancinemaaudiences.org, accessed 4 February 2020.

40 Thunnis Van Oort, Åsa Jernudd, Kathleen Lotze, Clara Pafort-Overduin, Daniel Biltereyst, Jaap Boter, Silvia Dibeltulo, Pier Ercole, Philippe Meers, Terézia Porubčanská, Daniela Treveri Gennari and Lies Van De Vijver, “Mapping Film Programming across Post-War Europe (1952)”, Research Data Journal for the Humanities and Social Sciences (in press, 2020). Data set: 10.17026/ dans-zed-2hg2.

41 Every film, cast and crew member and company registered on IMDb has a unique identifier that consists of a combination of letters ("tt”, for example, indicates a reference to a film title, "nm” a person's name, etc.) and digits. Whereas names or titles can be subject to change, the identifiers remain the same. Films that could not be identified, 70 out of 1556 unique titles, received a separate ID (JACK\#\#\#).

42 This is based on a decision made in the initial phase of the data collection by the research team of the 'Enlightened' City project.

43 In 1952, Rotterdam had 691,473 inhabitants and Schiedam had 74,406.

44 Thunnis van Oort, "Resurrection in Slow Motion". 

Cinema Market in the 1930s," Enterprise and Society 13, no. 3 (1 September 2012): 634-71, https://doi. org/10.1093/es/khr073; Van Oort, “Industrial Organization.”

46 The average of a set of numbers is the total of those numbers divided by the number of items in that set. The median is the central value that separates the higher half from the lower half of a data sample. When the average and the median are the same, the dataset is more or less evenly distributed from the lowest to highest values.

47 This is also a low number compared to other Dutch cities. According to the Dutch Cinema Alliance's (Nederlandse Bioscoopbond) 1952 Annual Report, the citizens of Amsterdam, The Hague and Utrecht would annually visit the cinema on average 15, 14, and 12 times respectively. In 1952, the three largest cities of the Netherlands, Amsterdam, Rotterdam and The Hague, counted 38, 13 and 26 cinemas, with 21,514, 9,821 , and 18,140 seats, respectively.

Unless indicated otherwise, the classification of persons in groups of exhibitors is based on the primary sources consulted when creating the dataset, where several names were recorded for one cinema (see Belgische Syndicale Kamer van Cinematographie/Chambre Syndicale Belge de la Cinematographie, “Liste des salles 35 mm existant à la date du 30 juin 1952 - mise a jour au 15 mai 1953." Report, Brussels, 1953; Chambre syndicale belge de la publicité cinématographique a.s.b.l./Union belge des annonceurs a.s.b.l., "Répertoire publicitaire du cinéma belge.” Report, 1954; M. Gogne, “Deskundig verslag inzake de heer Heylen. Rechtbank van eerste aanleg te Antwerpen.” Report, Antwerp, 22 June, 1959). In addition, some persons can also be grouped based on their double functions in several cinemas (see Dibbets, "Bioscoopketens in Nederland."

49 This confirms findings from a qualitative analysis of the 25 longest running films in Antwerp in 1952. See Kathleen Lotze, “Antwerpen Kinemastad. A Mixed-Method Investigation Into Film Exhibition and Experiences of Cinemagoing in Antwerp (1945-1995) With a Focus On the Rex Cinema Group,” diss. Antwerp: University of Antwerp, 2020.

50 See Lotze and Meers, “'They Don’t Need Me In Heaven.”

51 SOU 1951:1, p. 58. Statligt stöd åt svensk filmproduktion. [State Public Report 1951:1. State Support of Swedish Film Production] Stockholm: Nordiska bokhandeln. http://urn.kb.se/resolve?urn=urn:nbn:se:kb:sou-1448258

52 Göran, Bjelkendal, Göteborgs alla biografer: en resa i 100 år. Göteborg: Landsarkivet i Göteborg, 2009.

53 SOU 1951:1, p. 58. 
54 Ibid.

55 Göran Bjelkendal, Göteborgs alla biografer.

56 SOU 1951:1, p. 58.

57 Göran Bjelkendal, Göteborgs alla biografer.

58 Ibid.

59 Sveriges biografer: förteckning över biografer och biografägare 1956: utg. på grundval av material från Filmägarnas kontrollförening u.p.a. (Stockholm: Spectator, 1956), 25-26; Sveriges biografer 1947, 32-33.

60 Bjelkendal, Göteborgs alla biografer, 297.

61 Ibid., 131.

62 Ibid., 87.

63 Ibid., 226.

64 From the data set we can observe that cinemas in the AB Cosmorama chain screened new films from 20th Century Fox and MGM; the cinemas of Biograf AB Centrum screened new films from Columbia and Warner; and Fastighets AB Orion's cinemas screened new releases from Paramount. The 26 new films from UIP that were shown in Gothenburg in 1952 were screened at cinemas owned by both Fastighets AB Orion and AB Royal Films.

65 Van Oort, "Resurrection in Slow Motion."

66 André van der Velden and Thunnis van Oort, “De terugkeer van een sterk merk - Maatschappij Tuschinski en de wederopbouw van het Rotterdamse bioscoopbedrijf," Rotterdams Jaarboekje 6 (12th series) (2018): $152-75$.

67 Not counting the remotely situated Courzand venue that would only screen on Sundays and which did not advertise programming, see Judith Thissen and André van der Velden, “Op zoek naar de tweede helix: Over het milieubegrip en de ontrafeling van het DNA van de Nederlandse filmcultuur," TMG Journal for Media History 21, no. 1 (2018): 19-38, http://doi.org/10.18146/2213-7653.2018.336.

68 Van Oort, "Resurrection in Slow Motion."

69 It would be interesting to see whether the position of Victoria changed after 1955, when competition from the centre cinemas intensified, but we currently do not have the programming data that would allow us to further test this hypothesis.

70 For instance, 20th Century Fox films would only screen in Prinses, Luxor, Colosseum or Harmonie, so they were apparently excluded from the Tuschinski chain. 
71 From the time plot we cannot be certain if the screenings in Victoria and Luxor indeed were premieres, but we have confirmed that they were via newspaper sources: Het Vrije Volk, May 2, 1952; May 8, 1952; June 26, 1952.

\section{Biographies}

Clara Pafort-Overduin Clara Pafort-Overduin is lecturer and researcher within the department of Media and Culture Studies at Utrecht University. She works on popular film in the Netherlands. She is one of the founding members of HoMER, an international network of scholars devoted to the History of Moviegoing, Exhibition and Reception. She published several book chapters and articles on the popularity of national (Dutch) films. Together with economic historian John Sedgwick and marketing economist Jaap Boter she published on the peculiarities of the structure and development of the Dutch film market in the 1930s. Together with Douglas Gomery she wrote the student handbook Movie History: A Survey. (Routledge, 2011). She is a member of the editorial staff of TMG Journal for Media History.

Kathleen Lotze Kathleen Lotze teaches at the Netherlands Film Academy. Her research centres on digital humanity approaches to local and comparative cinema histories. She has been involved in research projects at different Universities in Germany, Belgium, the Netherlands and the UK since 1999, amongst which Cinema Context (University of Amsterdam), 'Enlightened' City (University of Antwerp), CREATE: Creative Amsterdam - An E-Humanities Perspective (University of Amsterdam) and European Cinema Audiences (Oxford Brookes University). For her PhD project Antwerp Cinema City, she focused on changes in film exhibition and experiences of cinemagoing in Antwerp between 1945-1995. Results of her work have been presented at international conferences and have been published in several peer-reviewed journals and books. Åsa Jernudd holds a Phd in Cinema Studies and is an associate professor in Media and Communication at Örebro University (Sweden). She is currently principal investigator of the project 'Swedish Cinema and Everyday Life: A study of cinema-going in its peak and decline (2019-2021)', financed by The Swedish National Research Council. The project involves interviews with elders about memories of film and cinema in Sweden in the 1950s and 1960s and the study of cinema locations and cinema programming, as well as the use of archival research to learn about film culture at the time. 
Thunnis van Oort is a media historian. He works as a post-doctoral researcher at the CREATE digital humanities research programme of the University of Amsterdam. He has taught at universities in Utrecht and Amsterdam, coordinated the Theatre and Media Studies track at Roosevelt University College, and visited Antwerp University as a Marie Curie Pegasus research fellow in 2015, as well as participating in the AHRC-funded project 'European Cinema Audiences' coordinated at Oxford Brookes University. He is managing editor of TMG Journal for Media History.

TMG Journal for Media History

Volume 23 No (1/2)/2020

DOI

https://dx.doi.org/10.18146/tmg.790

PUBLISHER

Netherlands Institute for Sound and Vision

\section{COPYRIGHT}

Each article is copyrighted @ by its author(s) and is published under license from the author(s). When a paper is accepted for publication, authors will be requested to agree with the Creative Commons Attribution 4.0 International License. 